\title{
Substance Use Disorders and Adolescent Psychopathology
}

\author{
Carla L. Storr, ScD, MPH, ${ }^{1,2}$ \\ Lauren R. Pacek, ${ }^{2}$ \\ Silvia S. Martins, $\mathrm{MD}, \mathrm{PhD}^{2,3}$
}

\begin{abstract}
Adolescence is a vulnerable developmental stage where significant changes occur in a youth's body, brain, environment and socialization, which may increase vulnerability to substance use, development of addiction, and psychiatric disorders. A co-occurrence of mental and behavioral disturbances with drug involvement in adolescence is common, as reflected in both a high risk for drug use in youth with mental illness and a high frequency of psychopathology among drug users. In this review we provide a broad and basic overview of some of the research evidence indicating a strong co-occurrence of drug use disorders (abuse and dependence) with externalizing and internalizing disorders, as well as a few other serious mental health conditions among adolescents. Increasing awareness and knowledge of the high probability of the co-occurrence of mental and behavioral disturbances with drug involvement informs the understanding of the etiology, course, and treatment of psychiatric problems among adolescents.
\end{abstract}

Key Words: adolescence, comorbidity, substance use disorder, psychiatric disorder Suggested Citation: Storr CL, Pacek LR, Martins SS. Substance use disorders and adolescent psychopathology. Public Health Reviews. 2012;34: epub ahead of print.

\section{INTRODUCTION}

Adolescence is a critical and vulnerable stage of development where significant changes occur in a youth's body, brain, environment and

\footnotetext{
${ }^{1}$ Department of Family and Community Health, University of Maryland School of Nursing, Baltimore, MD, 21201, USA.

${ }^{2}$ Department of Mental Health, Johns Hopkins Bloomberg School of Public Health, Baltimore, MD, 21205, USA.

${ }^{3}$ Department of Epidemiology, Columbia University Mailman School of Public Health, New York, NY, 10032, USA.
}

Corresponding Author Contact Information: Carla Storr at cstor002@ son.umaryland.edu, University of Maryland School of Nursing, 655 W Lombard Street Ste 645C, Baltimore, MD, 21201, USA. 
socialization, which may increase vulnerability to substance use, development of addiction and psychiatric disorders. The onset of substance use and mental and behavioral disturbances occurs for many during the adolescent years. Alcohol and nicotine obtained via the use of tobacco products are often the first and most frequently used substances among youth. Nicotine is frequently used repeatedly on a daily basis and risky or excessive alcohol consumption is a problem for some. Cannabis is one of the most commonly used illegal drugs among youth in the United States and in other countries, but rates of nonmedical use of prescription (pain relievers, tranquilizers, stimulants, and depressants) and over-the-counter medications are also alarming. ${ }^{1}$ For many, substance use transitions into developing problems associated with the use. The National Comorbidity Survey-Adolescent Supplement (NCS-A) conducted in the US between 2001 and 2004 estimates that approximately 36.6 percent of adolescent drug users meet criteria for substance abuse with or without dependence, ${ }^{2} 19.6$ percent of smokers meet criteria for nicotine dependence, ${ }^{3}$ and 27.5 percent of adolescent regular alcohol users developed alcohol abuse with or without dependence. ${ }^{2}$ This same survey also estimates that nearly half of American youth meet lifetime criteria for at least one psychiatric disorder, with half of these associated with severe impairment. ${ }^{4}$ Anxiety disorders were the most common condition (31.9\%), followed by behavior disorders (19.1\%), mood disorders (14.3\%), and substance use disorders (SUDs) (11.4\%).

Involvement with substances and mental and behavioral disturbances often co-occur among adolescents as reflected in both a high risk for substance use in youth with mental illness and a high frequency of psychopathology among substance users. One literature review of community studies estimated that 60 percent of youths involved with drugs had a comorbid psychiatric diagnosis. ${ }^{5}$ In addition, the evidence from extensive study of comorbidity of SUDs and psychiatric disorders among adult samples highlights the importance of the need to understand the onset and progression of psychiatric and substance use problems and disorders among youth. ${ }^{6-8}$

In this review we describe a framework often used for psychiatric disorders among adolescents, and then address some of the strengths and weaknesses of the research currently being used to study the comorbidity of SUDs and other psychiatric disorders. We then follow with a broad overview of some of the research evidence indicating a strong co-occurrence of SUDs with externalizing and internalizing disorders, as well as a few other serious mental health conditions among adolescents. After briefly describing some possible explanations for the comorbid condition, this review ends with recommendations for continued research to aid prevention and intervention efforts. The goal of this review is not to be exhaustive but to highlight the 
complexity of issues faced by researchers and the importance of the need to understand the phenomenon of comorbidity during the stage of life when these disorders emerge. Increasing awareness and knowledge of the high probability of the co-occurrence of mental and behavioral disturbances with substance use involvement can inform the understanding of the etiology, course, and treatment of psychiatric problems among adolescents.

\section{DISCUSSION}

One common theoretical framework for understanding psychiatric disorders among adolescents is the internalizing and externalizing model. ${ }^{9}$ Internalization is the propensity to express distress inwards. Common internalizing disorders during adolescence include mood disorders such as major depressive disorder (MDD), dysthymia, and anxiety disorders including generalized anxiety disorder, separation anxiety disorder, phobias, and obsessive-compulsive disorder. Conversely, the propensity to express distress outwards is known as externalization. Disruptive behavior disorders such as attention-deficit/hyperactivity disorder (ADHD), oppositional defiant disorder, and conduct disorder (CD) are common externalizing disorders during adolescence. SUDs also fall under the category of disruptive behavior disorders, but for this review we address the comorbid condition co-occurring with one or more of other externalizing or internalizing disorders, thus known as a dual diagnosis. Factor analytic studies suggest distinctions between internalizing and externalizing disorders, ${ }^{10-13}$ however, evidence also suggests a high co-occurrence between as well as among these disorders in adolescence. ${ }^{11-14}$ It appears that psychopathology cannot be reduced to a simple structure. Patterns are influenced by gender, age, persistence, and the constellation of diagnoses included. ${ }^{15,16}$ These inconsistent patterns might be a key to understanding the associations and sequencing across disorders. ${ }^{17}$

Since comorbidity implies that two disorders occur in the same individual simultaneously or sequentially, and that the interactions between the two disorders can affect the course and prognosis of either disorder, many studies have attempted to quantify and establish the temporal ordering of the comorbidity between SUDs and psychiatric disorders among youth. However, differences in the research design, samples, the assessment procedure and criteria used to identify 'cases', and other assessment issues (e.g., different informants, timeframe captured) often result in a wide variation of estimates and a limited depiction of the interplay and sequencing of symptoms and disorder development. Below we highlight some of the research issues faced by those studying comorbidity in adolescents and illustrate the diversity of research approaches taken by several selected studies. 


\section{Research designs and samples}

The most common study design used in the field of comorbidity research is the cross-sectional study. Cross-sectional studies report a strong positive association between substance use and psychiatric disorders but rely heavily on accurate recall or use participants of different ages to estimate the probable inter-relatedness and temporality. Retrospective lifetime prevalence may under-estimate how common psychiatric disorders are. ${ }^{18}$ Therefore, ideally to determine the comorbid relationship and order of onset of the disorders, researchers need to use prospective, longitudinal studies, in which adolescents are followed over long periods of time and monitored for the development of the disorders under investigation. A disadvantage to studying comorbidity using cohort studies is that they must be very large and have long follow-up time to accrue a sufficient numbers of cases.

The context of where the sample is drawn from and sample characteristics are important to consider in interpreting results and of course extremely important for generalization purposes. Policy and other environmental and social factors (e.g., taxation, minimum age laws, cultural morals and sanctions) can influence the availability and access to substances, thus patterns of specific substance use and SUD trajectories can vary among youth in different countries and even regions of a country. In addition, differences in the co-occurring rates and patterns of substance use and mental health problems have been found to vary by sex and age. ${ }^{19-22}$

Adolescents with comorbid disorders can be easily found in treatment facilities; an estimated 70 to 80 perent of youth seeking substance abuse treatment have one or more comorbid disorder. ${ }^{23}$ Strengths of studies coming from clinical sites often include the rigorous assessments of not only a broader array of disorders, but also, of diagnoses that conform to the structure of the International Classification of Diseases (ICD) and Diagnostic and Statistical Manual of Mental Disorders (DSM) systems. They are especially useful when exploring comorbidity with less common specific disorders (e.g., Obsessive-Compulsive Disorder). However, clinical samples cannot provide unbiased rates or estimates of risk factors for comorbidity as many youth do not receive treatment or are not treated in clinical settings. Individuals seeking help often have more severe symptomology, and more impairment than those who do not seek treatment. To reduce the potential for selection biases, it is also important to evaluate the comorbid relationship in general population samples.

Many population based epidemiologic studies conducted in the US, including some prospective longitudinal studies, have utilized regional samples, and findings may not be generalizable to the general adolescent 
US population (e.g., Great Smokey Mountains Study of Youth; Oregon Adolescent Depression Project; Teen Health 2000). ${ }^{19,24-26}$ Indicators of mental health are included in several US national surveys of youth, ${ }^{27-31}$ however the range of psychiatric disorders and identification of SUD, not only use, has been limited until recently. A main objective of the NCS-A was to provide empirical data of a wide range of psychiatric disorders from a nationally representative sample of US children and adolescents. ${ }^{32}$

Researchers from other countries have also shed evidence on the cooccurrence of mental health issues and substance use among adolescents. Some examples include the Ontario Health Study which was a crosssectional community survey of children four to 16 years of age, ${ }^{33}$ two famous New Zealand cohorts with long term follow-up: Christchurch Health and Development Study ${ }^{34}$ and the Dunedin Multidisciplinary Health and Development Study, ${ }^{35}$ and the Early Developmental Stages of Psychopathology Study that is following youth from Munich, Germany and surrounding areas over time and whose design features include linkage with a family supplement and neurobiological laboratory studies of highrisk subjects. ${ }^{36}$

\section{Assessment issues}

There are various approaches to assessing mental health conditions among youth; using instruments based on taxonomy or symptom scales. A psychiatric disorder diagnosed via the ICD or DSM schema requires specific criteria and signs of impairment. Issues can arise in how different studies apply and operationalize the criteria (not to mention that the DSM criteria have changed over time). For example, the NCS-A study has been criticized for using substance abuse symptoms to screen for dependence; as a result, it does not capture information on youth who meet criteria for dependence but never met criteria for abuse. ${ }^{37}$ Also worth noting is that meeting disorder criteria does not necessarily imply functional impairment nor capture a severity threshold. On the other hand, clinically significant symptoms below the count necessary to warrant a diagnosis can be associated with functional impairment and are often the precursor of an emerging disorder and subthreshold diagnoses of substance use problems have been associated with psychiatric symptoms. ${ }^{38,39}$

Other common approaches used to screen for psychopathology among youth utilize lists of symptoms that often map onto DSM criteria. ${ }^{40}$ Instead of classifying the presence or absence of a diagnosis, symptom scales are used to rank the probability of having emotional and behavioral problems that might require further evaluation, clinical services or preventive interventions. 
Though only approximating a psychiatric diagnosis, they may be useful in detecting syndromes and subclinical symptoms. Studies using data obtained from one such tool, the Youth Self-Report (YSR) developed by Achenbach, ${ }^{41}$ find emotional and/or behavioral problems to be associated with substance use. ${ }^{42-44}$ Problem behaviors have also been associated with a rapid development of nicotine dependence among youth who recently initiated smoking ${ }^{45}$ and with both single and multiple SUDs in early adulthood. ${ }^{46}$

It takes time and resources to assess a variety of psychiatric and SUDs. The number and array of diagnoses one wishes to assess accurately creates challenges for the design and administration and adds to the respondent burden. Lay interviewers can administer structured instruments to assess psychiatric disorders but training is required. Assessing the various substances youth can become involved in, especially as they become older and have increased opportunities and access to illicit as well as non medical prescription type drugs, as well as mapping abuse and dependence criteria for each substance type can easily become daunting. Many studies, instead of describing SUD ascribed to specific substances, use an 'any' SUD approach. However, the choice of what substance one uses to define the SUD may influence comorbidity patterns as different substances have different effects (e.g., stimulant versus depressive) and the reasons for use may also vary between individual (e.g., seeking a high versus self medicating). Comorbid associations between SUDs and externalizing disorders are often the strongest and the association between marijuana dependence and other psychiatric disorders is often weaker than those with alcohol or other drugs. ${ }^{19}$ Because of the low prevalence of many specific psychiatric disorders as well as SUDs resulting from certain substances, large sample sizes are needed for such specificity.

A controversial point in assessing substance use and psychiatric disorders is whether it is sufficient to rely only on adolescent self-reports. A youth's knowledge of their own behavior and emotions makes them a potentially important contributor to the assessment process; however, comorbidity patterns among emotional and behavioral syndromes have been found to vary with the informant and there may be differential reporting by parents and youth by ethnic groups. ${ }^{19,47}$ Studies may use different informant sources such as parent reports only, youth report only, or a combination. Algorithm diagnoses cannot replace clinical judgment of the significance and impairment attributed to the diagnoses, but studies suggest that the general patterns of comorbidity are not affected by whether the data is put together by a clinician or by means of a computer algorithm scoring a structured interview. ${ }^{21}$

Regardless of who the respondent is, another concern is how well does one distinguish and recall symptoms (potentially overlapping ones) over time. 
Recall is also an extremely important limitation to establishing a greater understanding of the temporal sequencing, persistence and even reoccurrence of disorders. To avoid recall bias and have more immediate clinical relevance for treatment purposes, assessments tend to capture symptom experiences over a short time frame (i.e., a point prevalence of previous 30 days, 3 month or 12 month period). Surveys, on the other hand, often inquire about cumulative lifetime experiences. Retrospective recall bias may be less of an issue among adolescents because they are reflecting back upon fewer accumulated years of life than adults, but special probes as those used in the NCS-A that have been found to help increase recall among adults might still be useful in helping the youth to recall their experiences more reliably. ${ }^{48}$

Another cautionary note relates to a limitation of the term comorbidity, as it does not distinguish between a multitude of different temporal relationships among disorders. Angold and colleagues suggested differentiating concurrent from successive comorbidity. ${ }^{14}$ In concurrent comorbidity, even if the time of onset and offset are not coterminous, the disorders must have at some point in time been present concurrently (or if not in time in phenomenology). This type of comorbidity is often captured in studies that have assessed point (current) prevalence. On the other hand, studies assessing lifetime prevalence may not determine if the disorders ever occurred simultaneously, suggesting that the term successive comorbidity may be more appropriate. Thus, when comparing results across studies comorbidity rates can be very different, probably because lifetime comorbidity although capturing a longer time period relays heavily on recall. However, lifetime prevalence based on retrospective age-of-onset reports from cross sectional studies may be used to help capture the development of comorbidity by distinguishing the onset versus the persistence of the disorders. ${ }^{17} \mathrm{An}$ even stronger design would be to study the temporal sequencing of lifetime and current disorders in a longitudinal cohort of adolescents as with the Early Developmental Stages of Psychopathology Study. ${ }^{49}$

Finally, caution must also be taken not to artificially elevate the rates for psychiatric disorders because of a tendency to establish a diagnosis before some of the psychiatric symptomatology secondary to the substance use abates. A diagnosis of a substance-induced mental disorder may be averted by observing the adolescent for a minimum of four weeks after discontinuing drug use. For example, cocaine-induced states need to be clearly differentiated from schizophrenia, mood disorders, and anxiety disorders. Ruling this out may be difficult for adolescents to establish on their own when they are self reporting symptoms on a survey with fewer probes than what might occur in a clinical assessment as they may not recognize the connection. 
As seen from the brief review of research issues above, the complexity of the subject matter increases the need for sophistication in how we study and understand it. It does not necessarily mean the literature is flawed, but caution should be taken when making inferences and generalizations based upon findings from different studies. Instead of relying on deductions about the onset of comorbidity obtained from adult studies fraught with recall biases, we need to obtain a clearer picture of what is happening during the developmental stages of youth as symptoms and behaviors onset to determine trajectories of persistence and severity. Evidence already suggests there are specific features of substance use and the psychiatric condition that merit attention and detailed prospective monitoring. Therefore, future research should, whenever possible, focus on longitudinal study designs that start collecting data in early childhood of representative samples of youth in order to disentangle premorbid pathways that lead to comorbid SUD and psychiatric disorders.

\section{Research Evidence}

Next our review highlights some of the evidence on the magnitude and the kinds of co-occurring psychiatric and SUDs reported in some selected clinical samples as well as population-based studies of adolescents. A search of the PubMed, PsychInfo and Scopus databases identified several clinical and general population studies published in the past 15 years that specifically included adolescent samples with comorbid substance use and psychiatric disorders. Search terms included specific internalizing and externalizing disorders (e.g., ADHD, anxiety, depression) and SUD (including substance abuse, substance dependence, drug abuse, drug dependence, alcohol abuse, alcohol dependence). A preference was given for studies using diagnoses obtained via structured interviews and epidemiologic studies that used probability/representative sampling. In addition, because our main focus was on SUDs, studies focusing on comorbid substance use/drug use and psychiatric disorders were excluded. We observed a tendency for some research teams to strictly focus (or at least only publish) on either externalizing or internalizing disorders, not always both, as well as often limiting the assay of substance disorder to the more commonly used substances (e.g., alcohol and cannabis).

Globally, national estimates of the overall occurrence of comorbidity are generally lacking as not all studies of adolescent samples focus on one of the comorbid disorders being SUDs per se, nor are structured diagnostic assessments routinely used to assess both the substance use and mental health status. In the US, the Oregon Adolescent Depression Project found that twice as many adolescents with a SUD also had a psychiatric disorder 
(66.2\%) compared to those with a psychiatric disorder who had a SUD $(31.3 \%) .^{50}$ More recently, the NCS-A study reported 40 percent of adolescents with one class of disorder also met criteria for another class of lifetime disorder. ${ }^{4}$ Hopefully, future publications of the NCS-A will provide greater distinction of specific comorbid patterns as the 40 percent is likely an over estimation of the kind of comorbidity we are focusing on (substance use and psychiatric disorders), as comorbidity between other internalizing and externalizing disorders where SUDs are not present also occurs. In the meantime, findings from a study of a probability sample of youth enrolled in a health maintenance organization provide some interesting insights. The patterns of comorbidity suggest that the comorbid relationship between a SUD and psychiatric disorder may vary by the type of substance (e.g., less with marijuana), by the type of SUD (e.g., less with abuse versus dependence), and by the type of psychiatric disorder (e.g., strongest for behavioral disorders).${ }^{19}$ Some of these patterns have also been seen in adult data and may also extend to subthreshold disorders as well. ${ }^{50,51}$

The type of psychiatric paychopathology most commonly diagnosed in adolescents with SUDs are the externalizing disorders. ${ }^{53}$ Clinical studies document a high degree of co-occurrence of ADHD and CD among adolescent samples with SUDs (Table 1). Since many of the samples were derived from treatment programs a wide array of substances were included under the any SUD classification as youth having problems with one substance type often are using other substances as well. The sample variation in age, sex and other factors, such as racial mix, inner city versus rural setting, or type of program or center in which the research was performed result in a wide range of comorbid rates. However, these clinical studies indicate the importance of exploring subgroup variation. For example, gender differences were often greater among those with comorbid ADHD and alcohol disorder than with comorbid $\mathrm{CD}$ and alcohol disorder. Additionally, race/ethnicity differences were observed among youth with SUD, indicating that Whites, Hispanics, individuals of mixed race, and individuals endorsing "other" race exhibited greater rates of either ADHD or CD than did African Americans or American Indian/Alaskan Natives with SUD.

Congruent with findings from clinical studies, evidence from epidemiologic studies of various designs indicate the comorbidity between externalizing disorders and SUDs in adolescents exists in the general population as well (Table 2). These studies also show that in addition to ADHD and CD, oppositional defiant disorder (ODD) commonly co-occurs with SUD in the adolescent population. ${ }^{22,54-58}$ Many of the SUD disorders are substance specific or the any SUD is based on the more commonly used substances at younger ages: nicotine, alcohol and cannabis. Several of the 


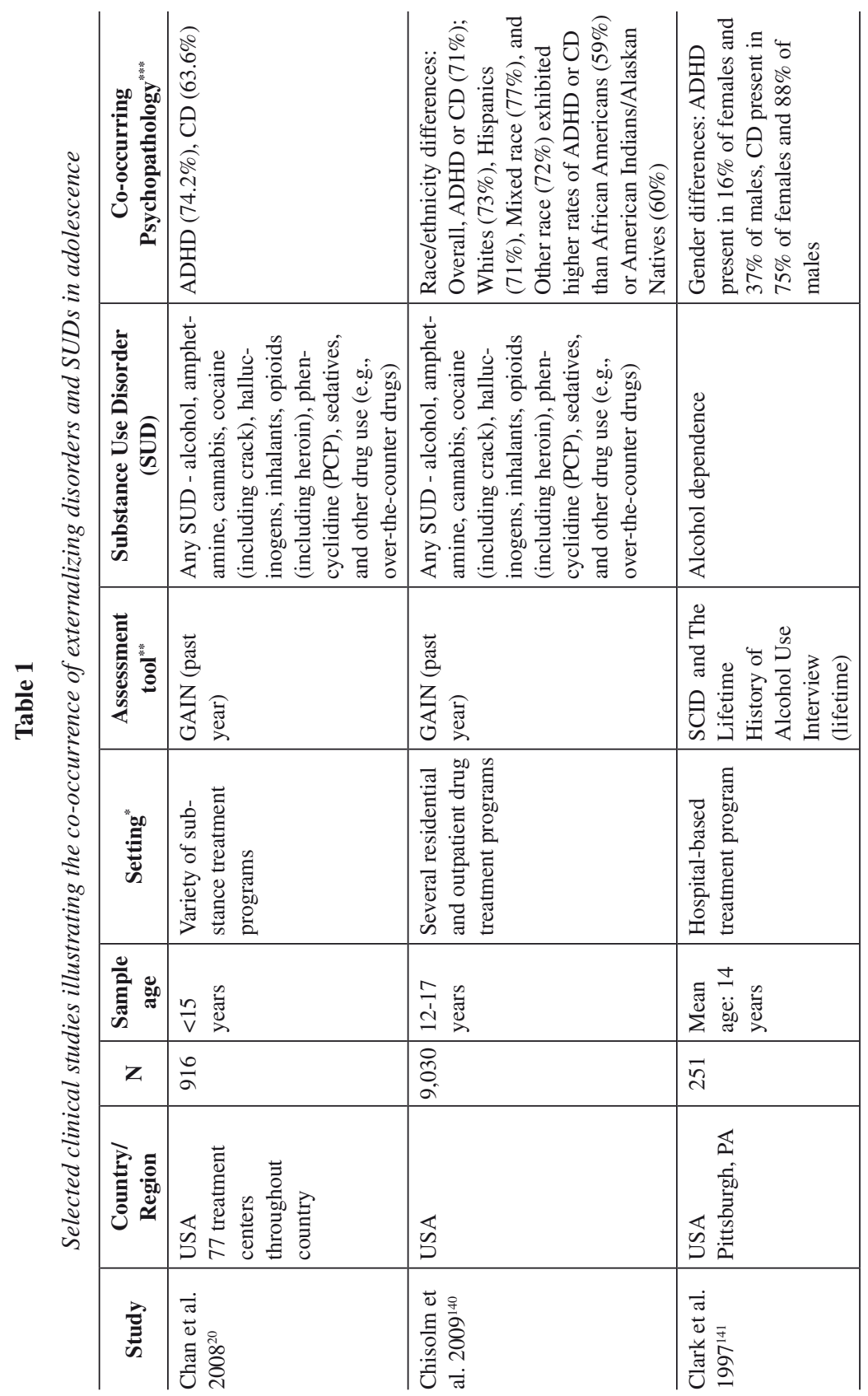




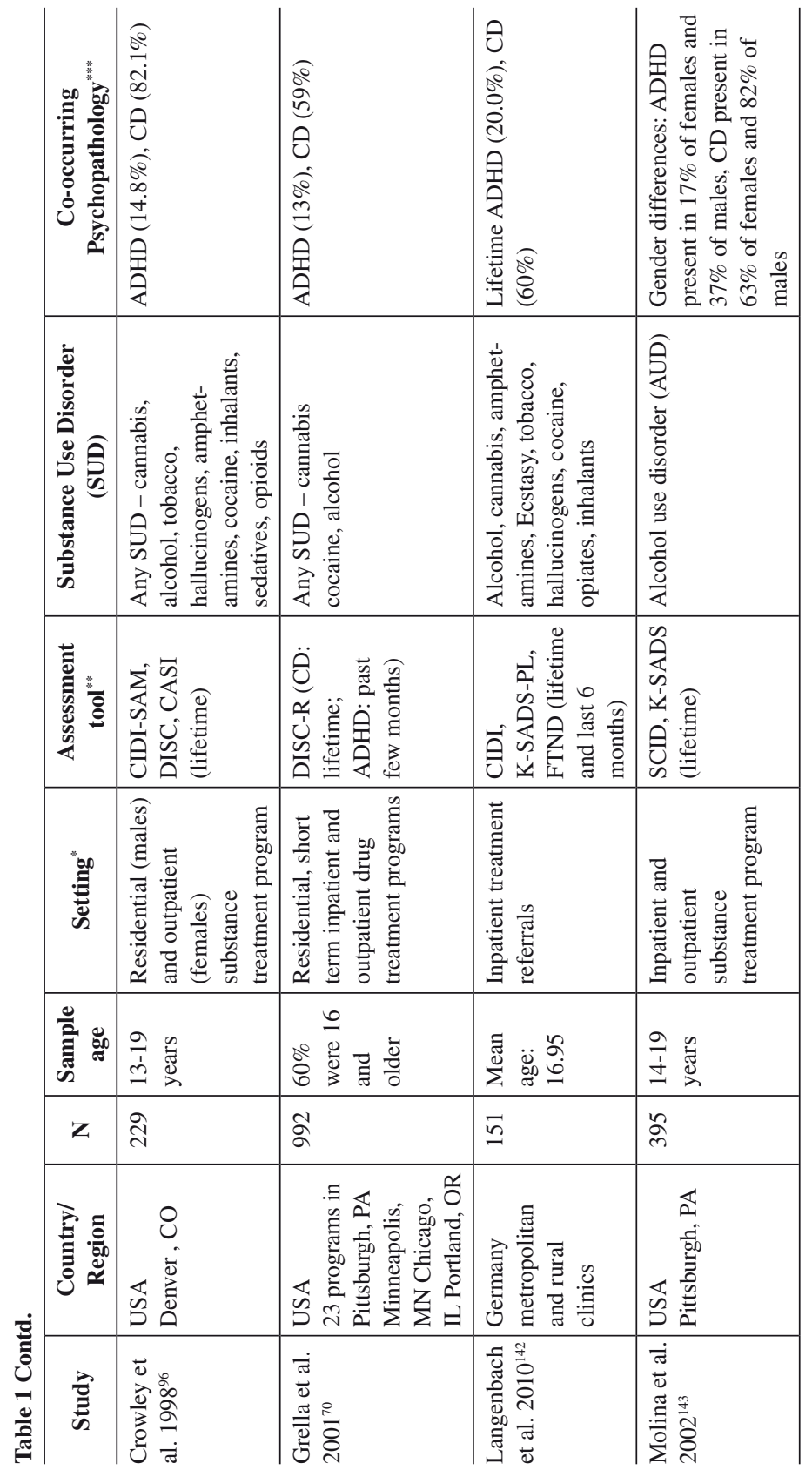




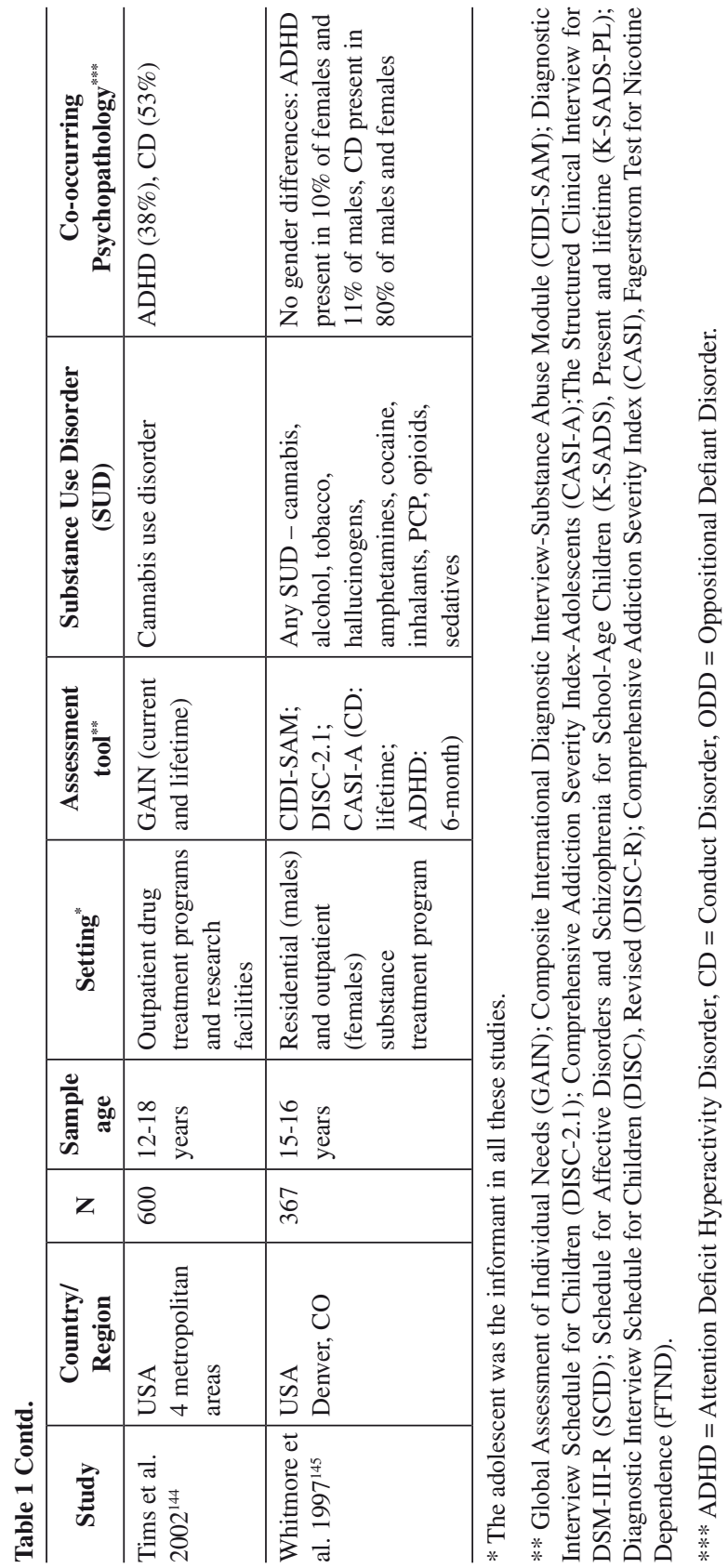




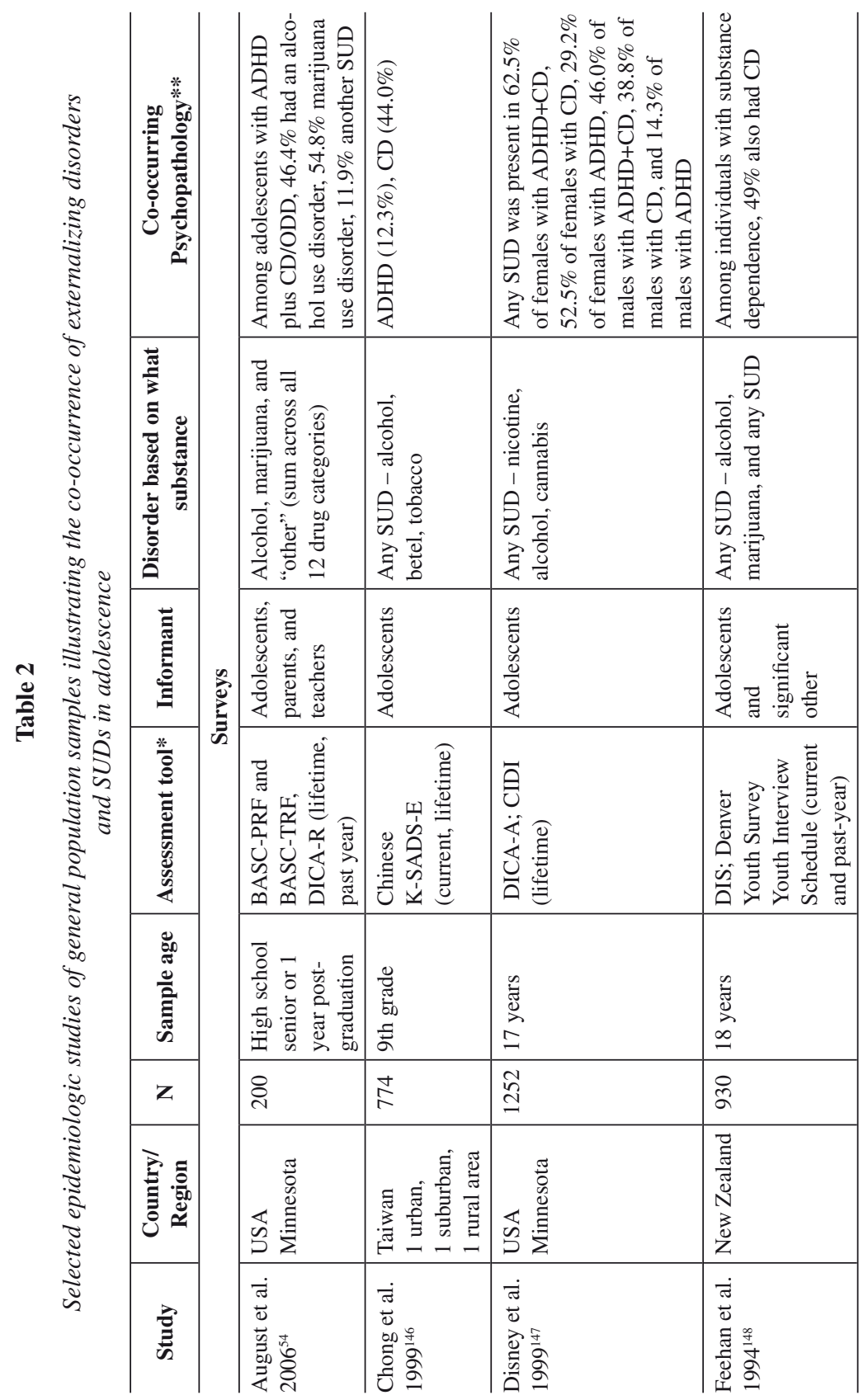




\begin{tabular}{|c|c|c|c|c|c|}
\hline 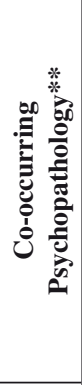 & 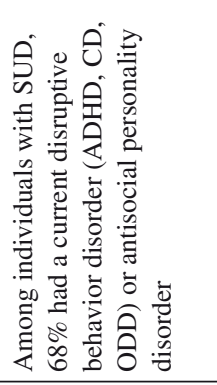 & 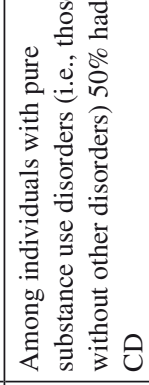 & 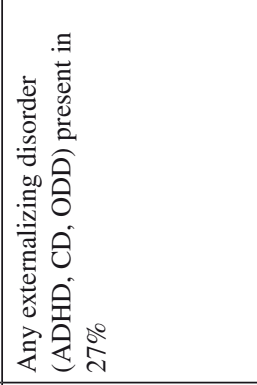 & 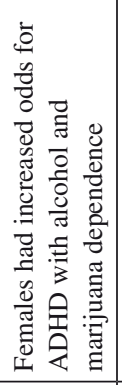 & 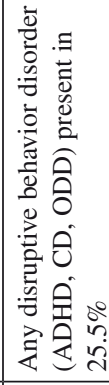 \\
\hline 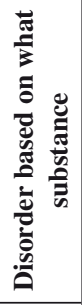 & 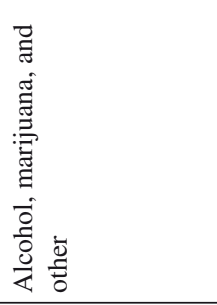 & 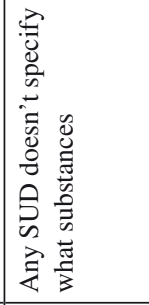 & 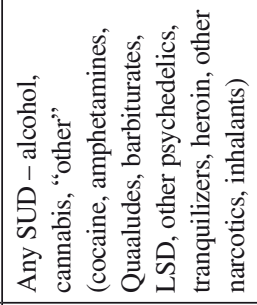 & 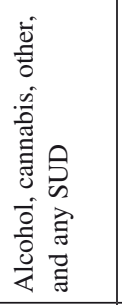 & 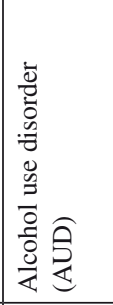 \\
\hline 焉 & 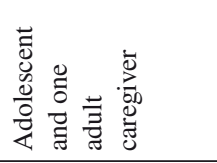 & 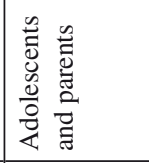 & 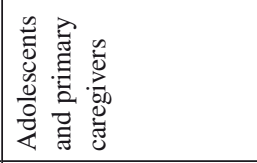 & 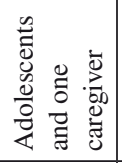 & $\begin{array}{l}\frac{n}{0} \\
\frac{0}{0} \\
\frac{0}{0} \\
\frac{0}{0} \\
\frac{0}{<}\end{array}$ \\
\hline 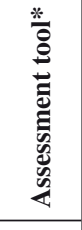 & 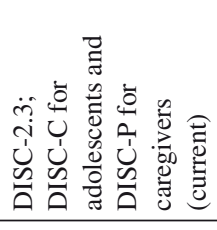 & 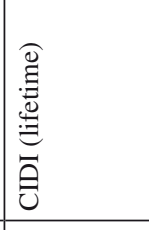 & 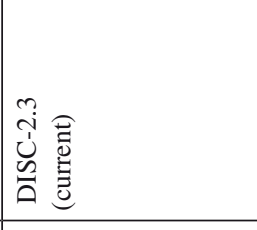 & 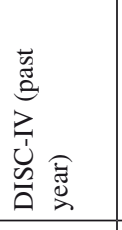 & 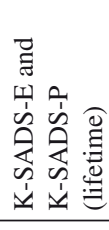 \\
\hline 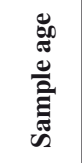 & 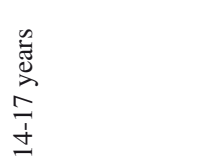 & 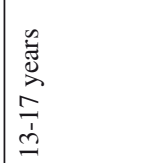 & 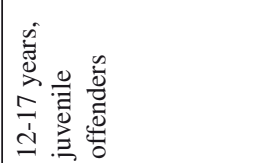 & 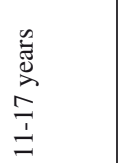 & 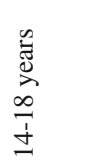 \\
\hline z & 字 & $\stackrel{\substack{\infty \\
\sigma}}{0}$ & $\stackrel{\infty}{=}$ & 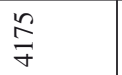 & $\stackrel{\Xi}{\stackrel{2}{ }}$ \\
\hline $\begin{array}{l}0 \\
0\end{array}$ & 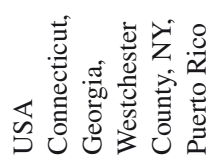 & 范 & 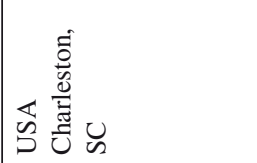 & 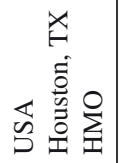 & 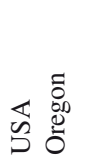 \\
\hline 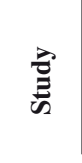 & 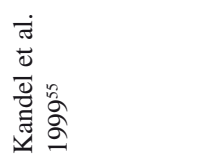 & 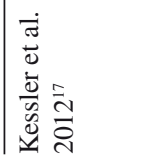 & 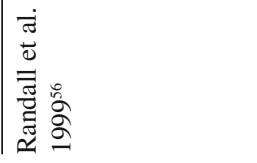 & 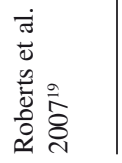 & 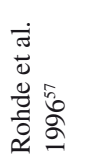 \\
\hline
\end{tabular}




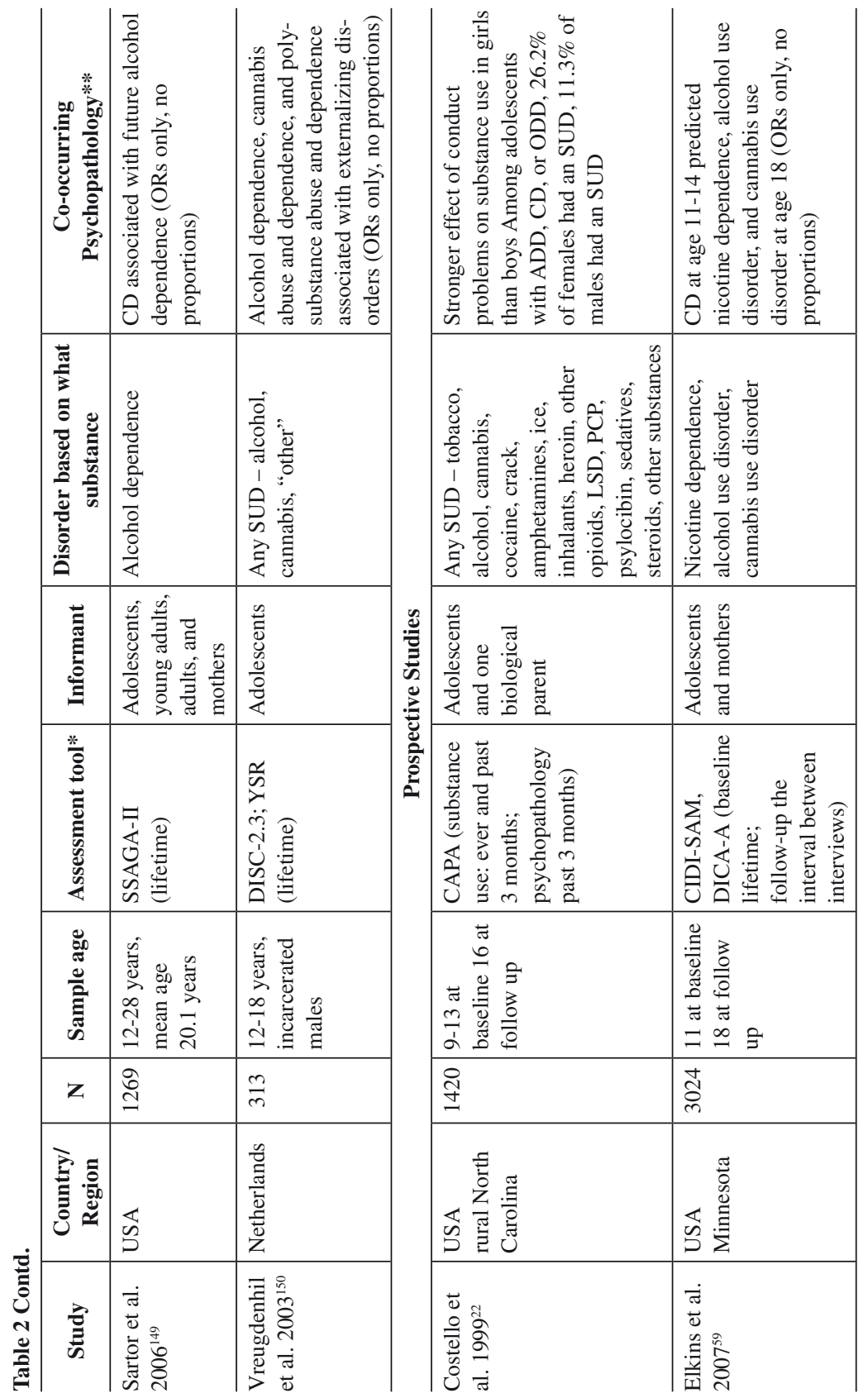




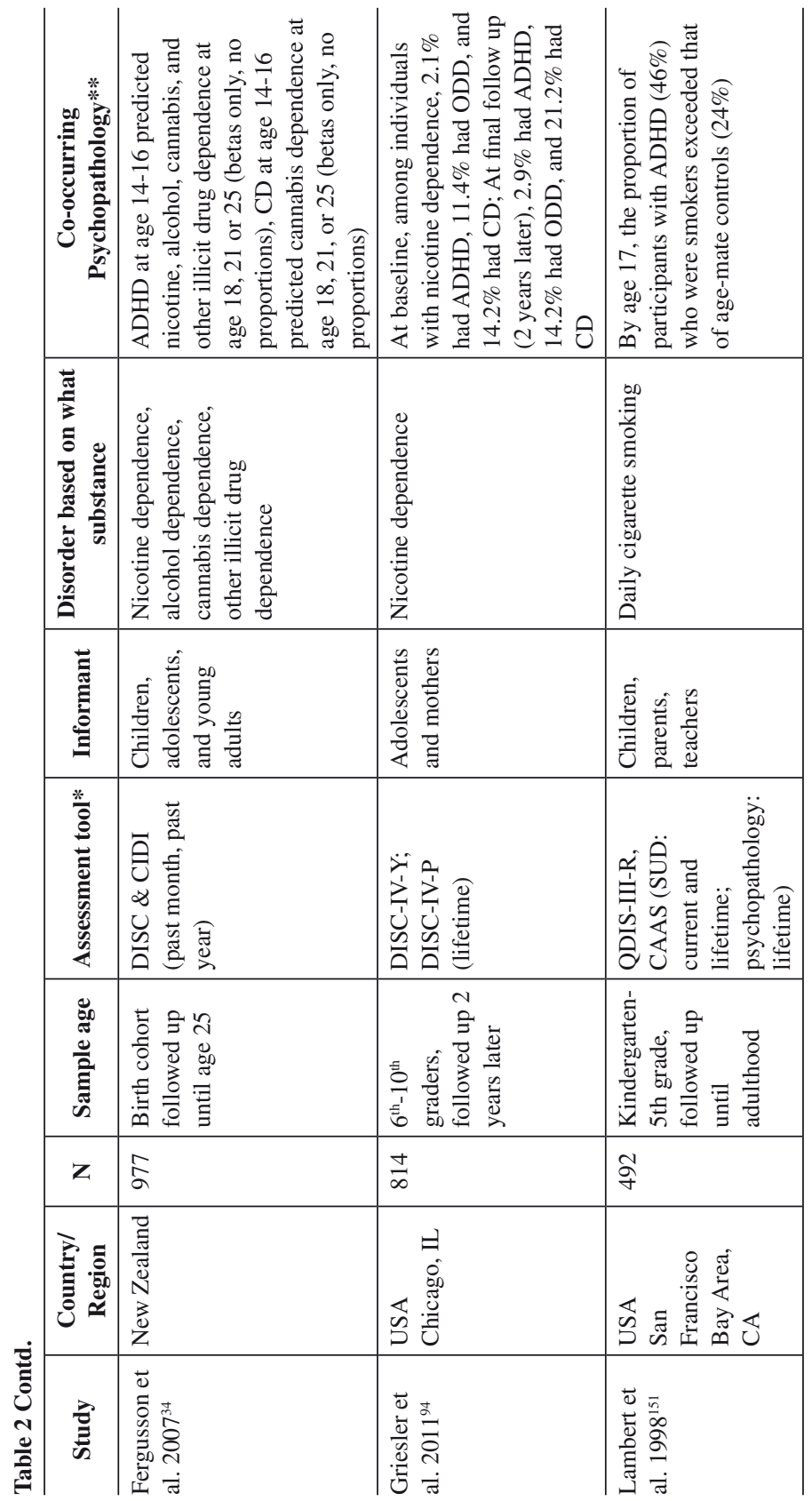




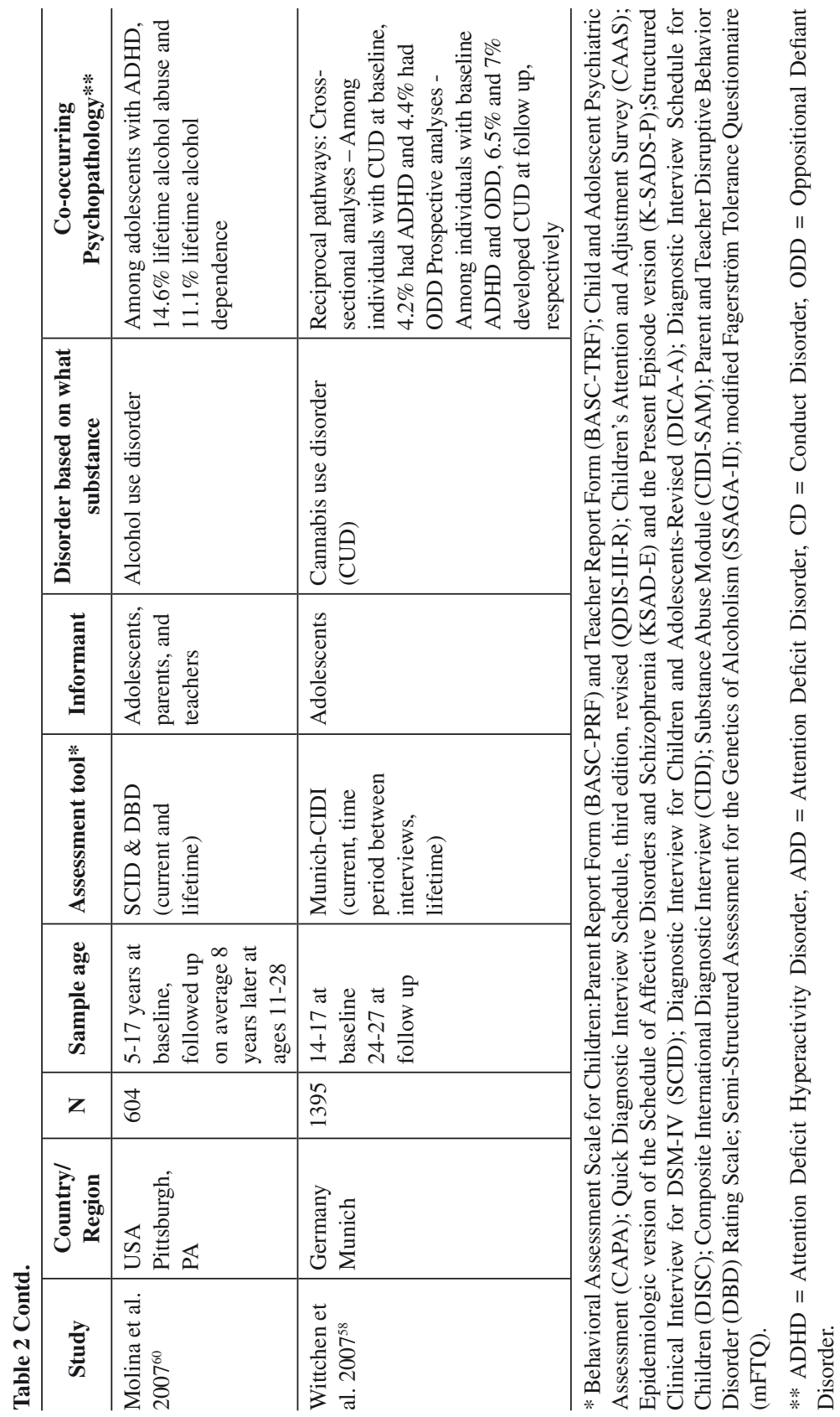


epidemiologic studies include information obtained from other informants when making diagnostic classifications. Evidence from several of the longitudinal studies analyzing the co-occurrence prospectively find that the onset of externalizing psychopathology tends to precede the development of SUDs. ${ }^{34,59,60}$

In addition to descriptions of categorical classifications of externalizing psychopathology, a body of literature exists that describes how specific components or symptoms and personality traits are associated with substance use and SUDs in adolescence. In particular, many studies find that aggressive behavior, a component of $\mathrm{CD}$, and violence accompany and often precede adolescent substance use and SUD. ${ }^{61-64}$ Additionally, impulsivity, one of the components of ADHD, is often associated with initiation of alcohol use in adolescence,$^{65}$ while hyperactivity in childhood is associated with a greater likelihood of being arrested in young adulthood for charges stemming from illegal drug possession, use, and sale. ${ }^{66}$ Furthermore, it is possible that reciprocal relationships exist between psychopathological symptoms and substance use behaviors, as certain drugs, such as alcohol, anabolic steroids, benzodiazepines, and cocaine can escalate the development of aggression and violent behavior.

Evidence of a high prevalence of a co-occurrence between internalizing disorders and SUDs is also shown in both clinical and epidemiologic studies. ${ }^{53,67}$ A review found evidence that comorbidity rates are higher in samples of adolescents where SUD appeared first than among youth where internalizing disorders preceded the onset of other disorders. ${ }^{67}$ Table 3 provides some examples of clinical-based research where high rates of internalizing disorders, particularly MDD, are often found among adolescent samples who are in treatment for SUDs. On the other hand, adolescents in treatment for psychiatric disorders also have comorbid SUDs. ${ }^{68}$ Modest rates of anxiety disorders, especially posttraumatic stress disorder, are also often found among youths with SUDs, ranging from six percent to 38 percent. ${ }^{69,70}$ Studies also find comorbidity between SUD in adolescence and bipolar disorder. ${ }^{71,72}$ As seen in the clinical studies of externalizing disorders, the substances included in the disorder category vary across studies, as do sample characteristics. Gender differences were noted by a few of the studies where females tend to have higher rates of comorbidity between SUDs and internalizing disorders than males.

Numerous epidemiologic studies find mood and anxiety disorders strongly associated with SUDs in more general population samples of adolescence (Table 4). In many of these studies the SUD disorders are substance specific but in some studies the SUD includes other illegal drugs that are sometimes not specified as to what particular type of substances 


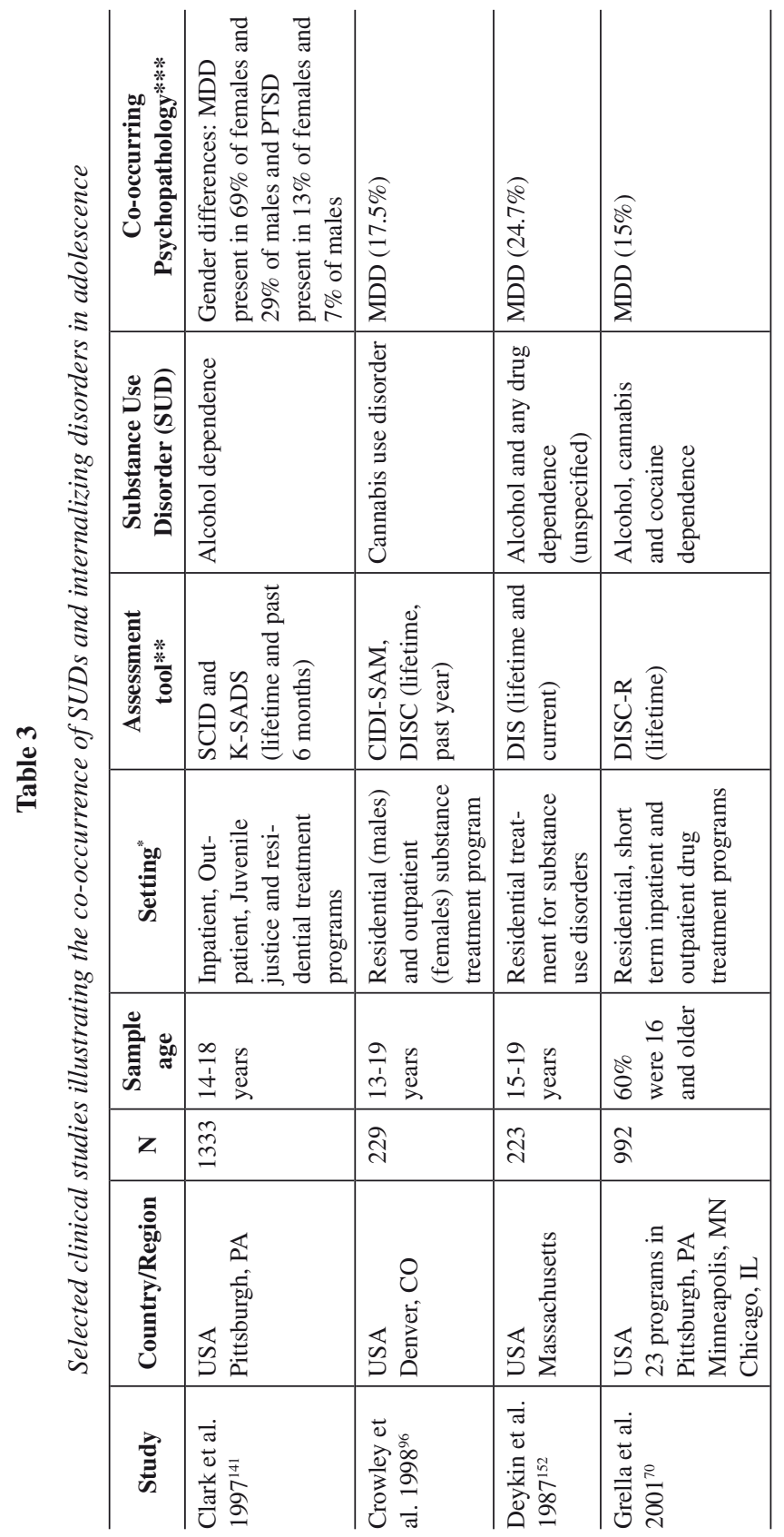




\begin{tabular}{|c|c|c|c|}
\hline 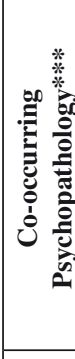 & 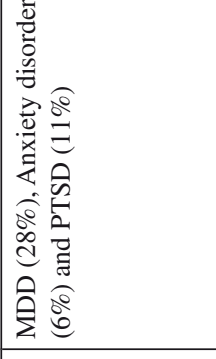 & 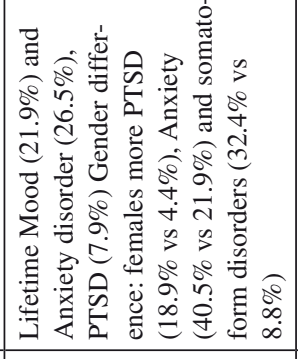 & 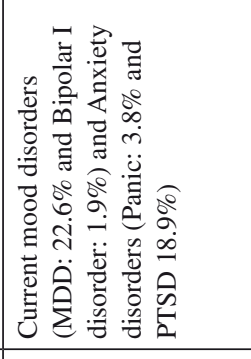 \\
\hline 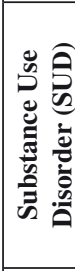 & 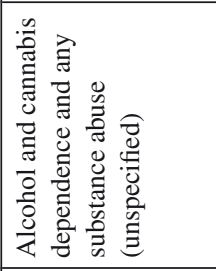 & 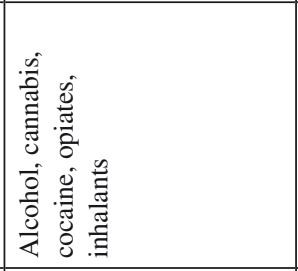 & 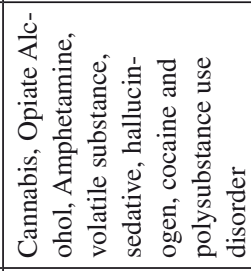 \\
\hline 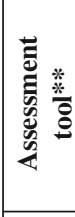 & 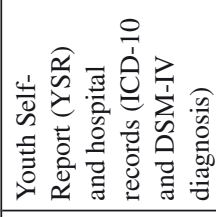 & 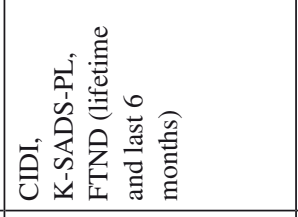 & 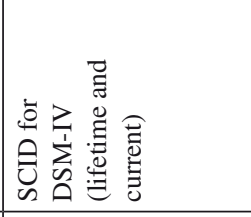 \\
\hline 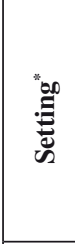 & 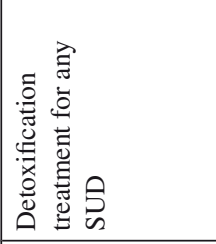 & 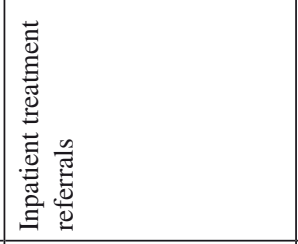 & 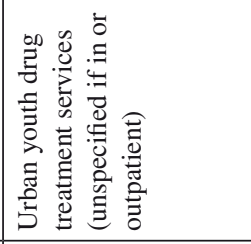 \\
\hline 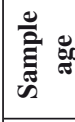 & 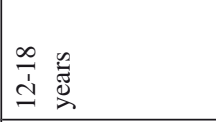 & 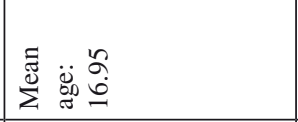 & 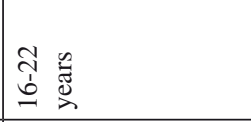 \\
\hline $\mathrm{z}$ & $\hat{\varrho}$ & 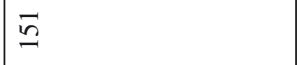 & 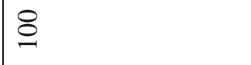 \\
\hline 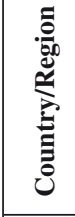 & 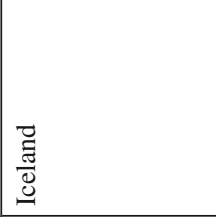 & 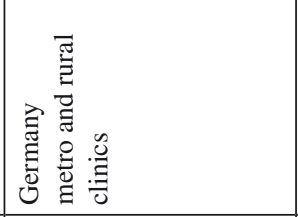 & 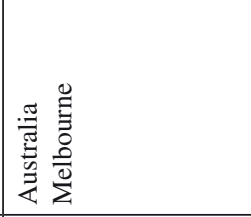 \\
\hline$\stackrel{\vec{E}}{E}$ & 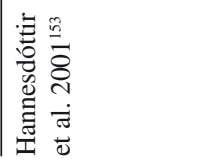 & 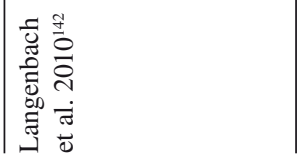 & 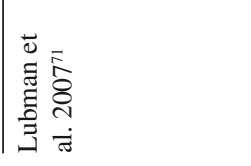 \\
\hline
\end{tabular}




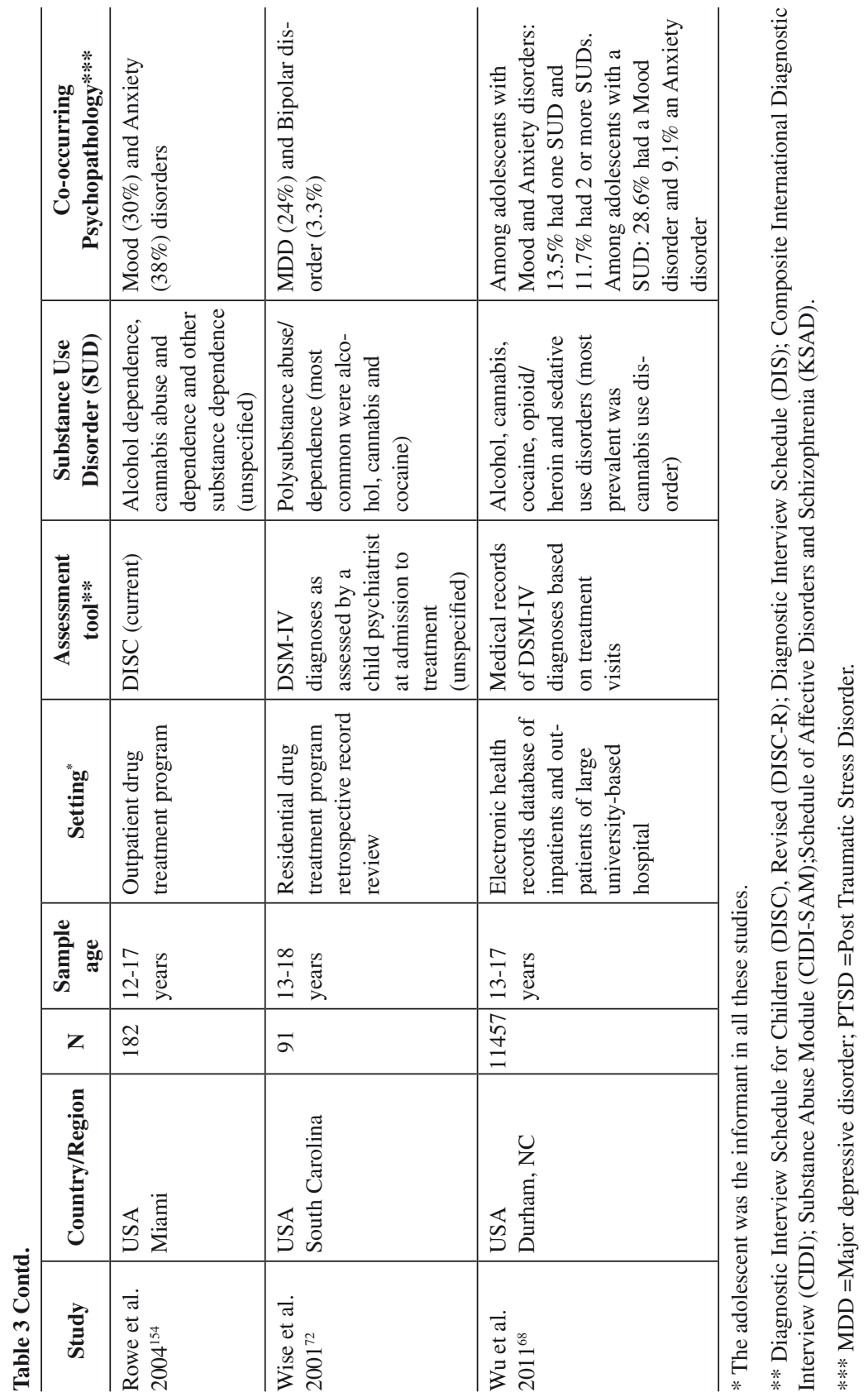




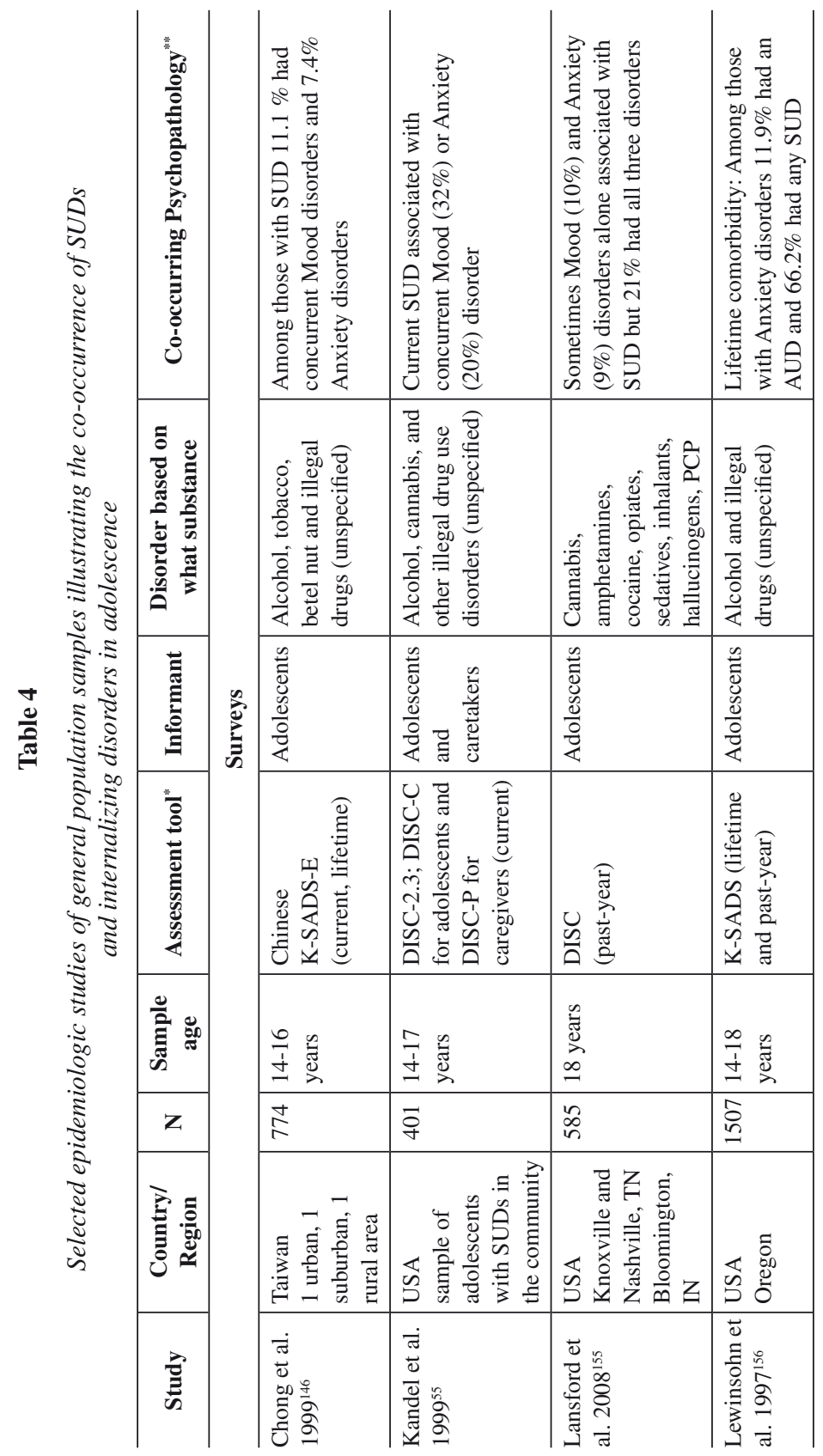




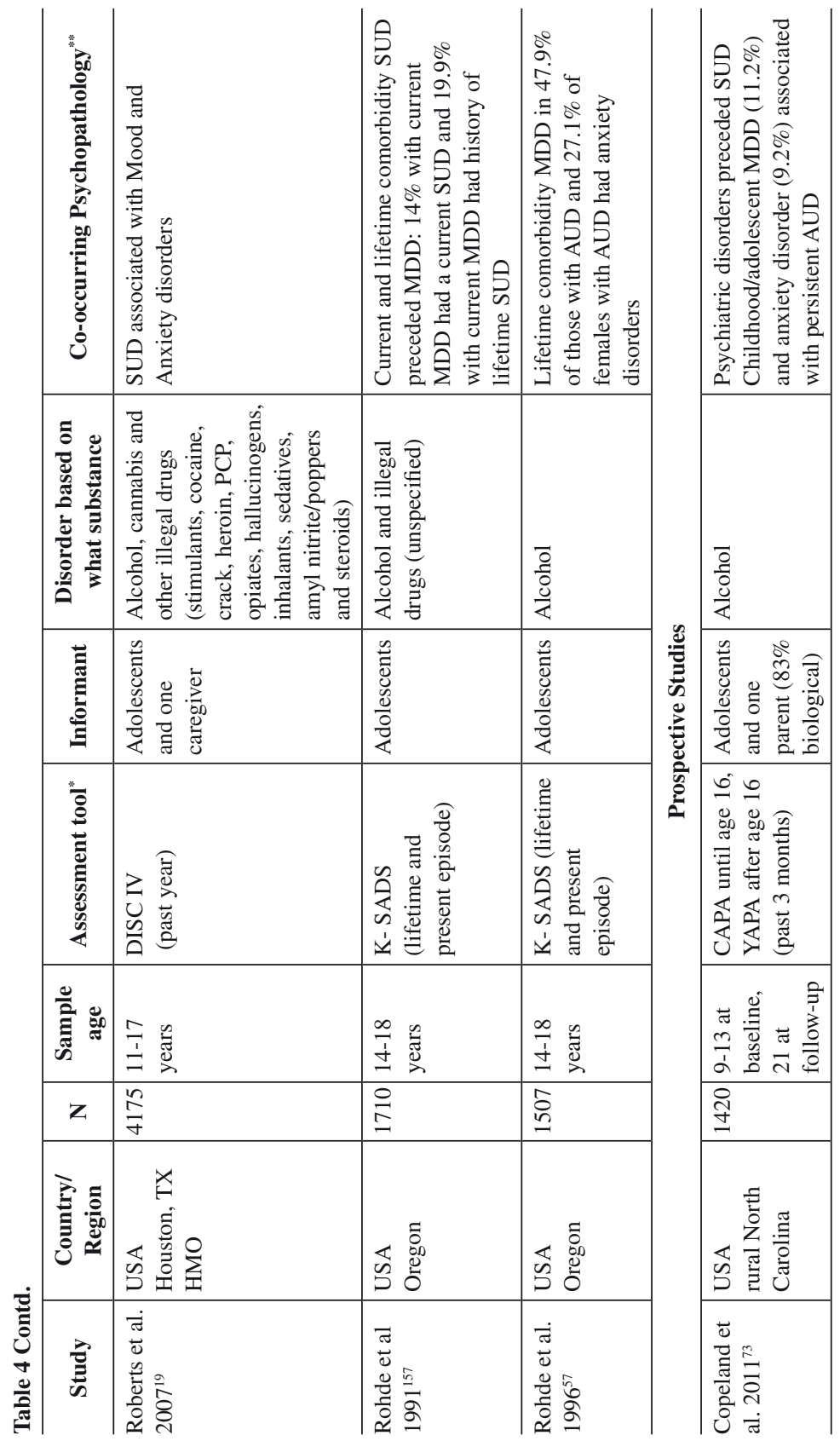




\begin{tabular}{|c|c|c|c|}
\hline 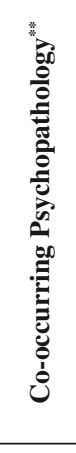 & 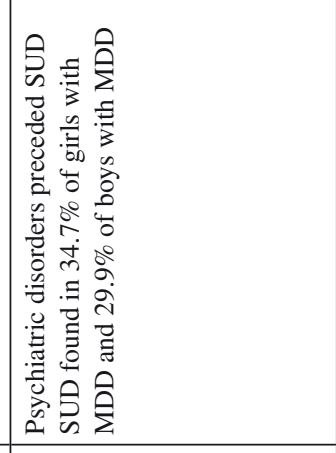 & 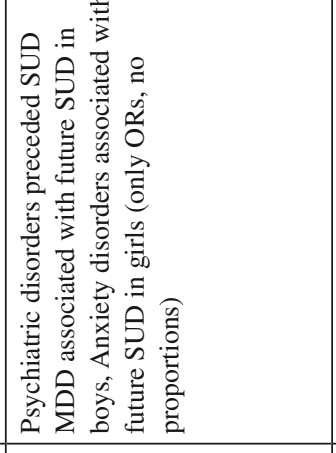 & 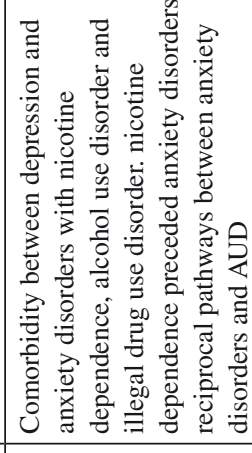 \\
\hline 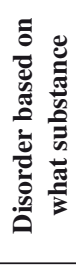 & 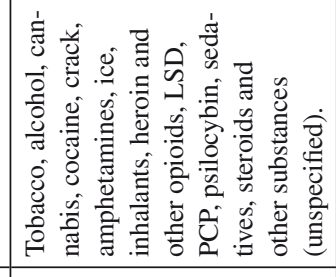 & 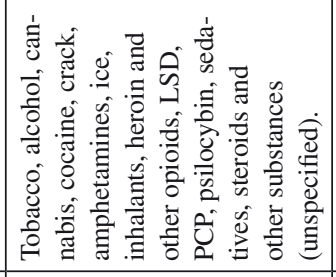 & 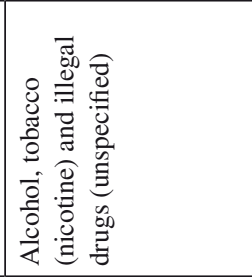 \\
\hline 䓂 & 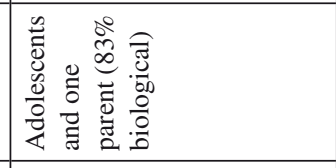 & 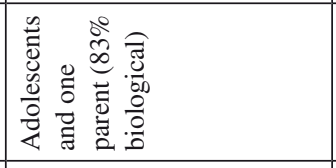 & 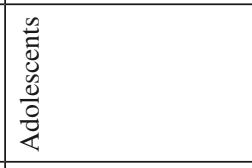 \\
\hline 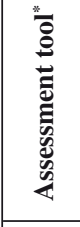 & 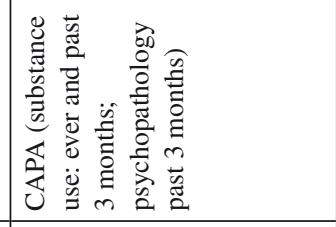 & 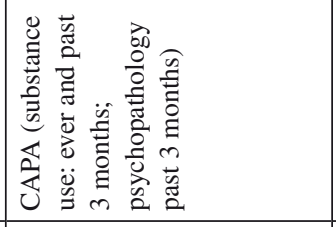 & 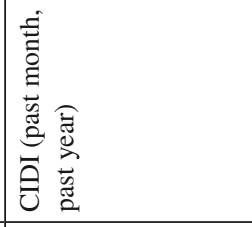 \\
\hline 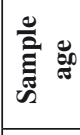 & 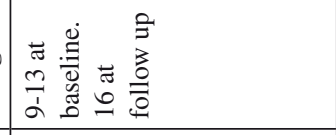 & 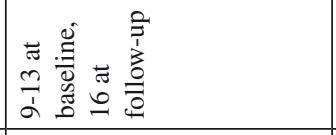 & 资 \\
\hline z & 害 & 荨 & nू \\
\hline "َd & 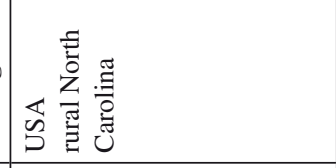 & 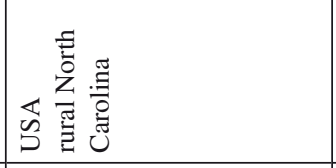 & 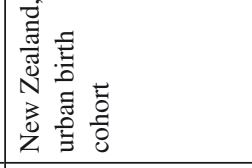 \\
\hline 竞 & 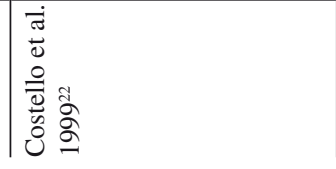 & 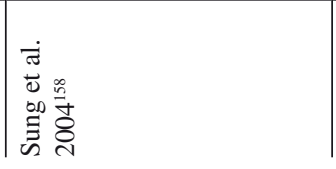 & 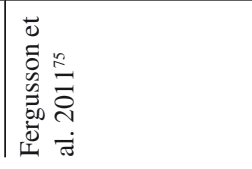 \\
\hline
\end{tabular}




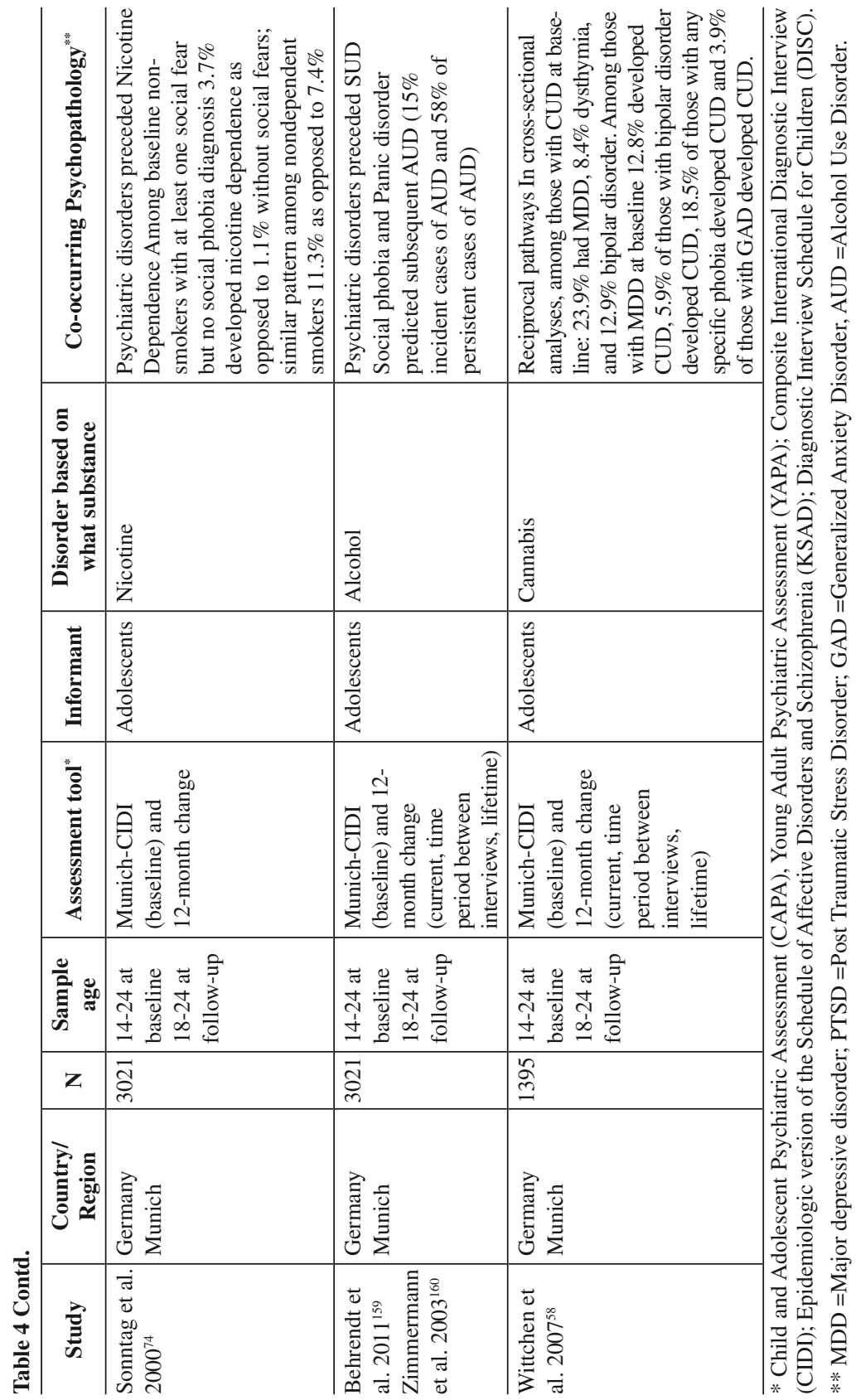


were included. A few of the studies included information obtained from a caregiver in addition to reports by the adolescent when deriving disorder classifications. Many of the longitudinal studies indicate that the onset of internalizing disorders precedes the onset of SUDs, ${ }^{22,73,74}$ while others argue for reciprocal pathways between SUDs and internalizing disorders. ${ }^{58,75}$

Late adolescence and early adulthood are also peak periods for the onset of other serious mental illnesses and abnormal/maladaptive behavior. Excessive use of drugs and/or alcohol are very common among youth with schizophrenia. ${ }^{76,77}$ Cannabis, amphetamine, cocaine, and to a lesser extent alcohol, are associated with psychosis. ${ }^{78-80}$ Eating disorders are frequently associated with substance use and are common among adolescents having SUDs. ${ }^{81,82}$ It has been speculated that young women with anorexia may initiate drug use in an effort to lose weight and that those with bulimia nervosa may be turning to substances to dampen purging symptoms and behaviors. ${ }^{83}$ SUDs and sleep disorders also often co-occur and have a significant negative effect upon normal development and are associated with deleterious effects on mood, attention, and behavior. ${ }^{84,85}$ In addition, there is accumulating evidence from clinical and epidemiological studies on the link between drug use and suicide among adolescents, ${ }^{86,87}$ with comorbidity increasing the risk for suicidal behaviors. ${ }^{88}$ Alcohol abuse and dependence, cigarette smoking and cannabis use have been found to be associated with suicide attempts among adolescents..$^{89,90}$ The intoxicating effects of drug use might lead to impairments in judgment or changes in mood which then increase risk for suicidal ideation and attempt ${ }^{91}$ and alcohol-specific effects such as disinhibition and emotional or behavioral problems (dysphoria, impulsivity, and aggression) have been implicated in suicidal behaviors. ${ }^{92}$

While a goal of many studies is to make available evidence on the temporal order and sequencing of onset of substance use and disorder and the various psychiatric disorders, publications often do not include descriptives of the ages of onset. Table 5 summarizes the age of onset for major disorder groups described by several adolescent studies. Whereas sequencing can vary on an individual basis, the evidence appears to indicate that on average anxiety and behavior disorders precede SUDs, while there is less time differential between mood disorders and SUDs. On average, psychiatric disorders also precede nicotine dependence by at least two years. ${ }^{22,93,94}$ Paths to comorbidity have been noted to differ by sex..$^{22}$ In addition, sensitivity to distinct trajectories may be warranted as externalizing disorders typically have onset in childhood or adolescence and then may persist into adulthood or decrease with age, while the onset of internalizing disorders occurs over the life course with their cumulative prevalence generally increasing with age. 
Table 5

Estimated onset of psychiatric and SUDs

as established by several adolescent studies

\begin{tabular}{l|c|c|c}
\hline US Study: & $\begin{array}{c}\text { Costello et al. } \\
\mathbf{1 9 9 9 2 2}^{22}\end{array}$ & $\begin{array}{c}\text { Merikangas et al. 2010 } \\
\text { and Swendsen et al. 2012 }\end{array}$ & $\begin{array}{c}\text { Griesler et al. } \\
\mathbf{2 0 1 1}^{\mathbf{9 4}}\end{array}$ \\
\hline Design/sample: & $\begin{array}{c}\text { Rural longitudinal } \\
\text { cohort }\end{array}$ & National survey & $\begin{array}{c}\text { Urban longitudinal } \\
\text { cohort }\end{array}$ \\
\hline Measure: & Age first symptom & Median ages & Mean ages \\
\hline Anxiety Disorder & 3.8 & 6 & 10.7 \\
\hline Behavior Disorder & 5 & 11 & 10.6 \\
\hline Mood Disorder & 10.1 & 13 & 11.7 \\
\hline $\begin{array}{l}\text { Substance Abuse/ } \\
\text { Dependence }\end{array}$ & 14.5 & $14-15^{*}$ & $14.7^{* *}$ \\
\hline
\end{tabular}

* Includes Alcohol and other drugs.

** Tobacco dependence.

In summary, numerous studies establish a comorbid association, but population estimates of how many, the when, and which youth are affected are scarce. In addition, more childhood and adolescent studies on the sequencing of the disorders, as well as how and the conditions under which the behaviors and mood conditions develop, are needed to obtain a greater understanding of the trajectories that will inform opportunities for prevention and intervention.

\section{Possible explanations}

There are several possible explanations of why there is a connection between substance use and mental illness. Empirical research supports the existence of risk factors from multiple domains hypothesized in the social development model, ${ }^{95}$ such as one's individual attributes, attitudes and opportunities, family or household structure and recent life events. Problem behavior syndrome and an array of complementary conceptual models link externalizing type behaviors such as aggression, rule breaking, and other socially maladaptive behaviors with tobacco use and drug-taking. ${ }^{96-100}$

The co-occurrence adds a complexity to understanding the intricate relationship and etiology. Understanding the sequencing behind the high prevalence of co-occurrences of drug abuse and psychopathology is not simple; one cannot assume just because one appeared first that it caused the other. Often emotional and behavior problems are found to precede drug use. ${ }^{101-103}$ Externalizing behaviors have been associated with the progression 
of drug use, whether progression in stage of use within a particular drug ${ }^{104}$ or becoming involved with other drugs, such as marijuana and inhalants. ${ }^{105,106}$ This suggests some youth may be using drugs to self medicate. However, evidence that drug use precedes mental health outcomes also exists. Substance use and drug-related problems have both been shown to relate to disruptive behavior diagnoses. ${ }^{107,108}$ Mood changes are a common feature during withdrawal from several drugs of abuse. ${ }^{109}$ The shared liabilities of drug use disorders and other mental illnesses may also be due to genetic as well as environmental influences. ${ }^{110-114}$ Family-genetic studies provide evidence of linkage between depression and drug abuse and substance disorders. ${ }^{115,116}$ Alterations in reward and motivational processes might play a central role in the manifestation of core symptoms of both drug and psychiatric disorders. ${ }^{117,119}$

Many theories and models of comorbidity have been postulated. These models often include multiple domains and highlight that there may be several different mechanisms and routes leading to comorbidity. New collection efforts should also seek to incorporate genetic as well as environmental influences that may impact the onset of comorbidity and allow study of the complex genetic interactions between a wide array of environmental factors.

\section{RECOMMENDATIONS}

The presence of high co-occurrence of externalizing and internalizing disorders among youth abusing drugs and alcohol deserves attention to detect and provide appropriate treatment and referral for these problems as the burden of this comorbidity is significant. Previous reviews of adolescent outcomes found strong evidence that this comorbid combination was associated with truancy, rebelliousness, academic problems, and school drop out. ${ }^{14,24}$ In addition, other studies point to the added economic and psychosocial burden of having comorbid disorders, and less overall well being, including higher levels of psychopathology, suicidal ideation, and greater functional impairment. ${ }^{19,120-122}$ Further substantiating the importance of the need for prevention and early intervention among the adolescent years is the continued impact of comorbidity on young adult roles and behaviors. Comorbidity has been found to be associated with arrests, continued drug use, and reductions in work productivity ${ }^{49,123}$ and among HIV-infected individuals with decreased odds of highly active antiretroviral therapy (HAART) utilization and viral suppression. ${ }^{124}$ Having both psychiatric and SUDs increases impairment and results in poorer prognosis. 
Complications of co-occurring disorders on treatment outcome are also well-documented, as the complexity of problems may impair an adolescent's ability to effectively engage in treatment ${ }^{125}$ and can increase the rate and rapidity of relapse. ${ }^{126}$ Findings have shown that many substance abuse treatment clients with less serious psychiatric disorders do well with traditional substance abuse treatment methods, while those with more serious psychiatric disorders need intervention modifications and additions to enhance treatment effectiveness. ${ }^{127}$ The US Center for Substance Abuse Treatment has published best-practice guidelines for treating and recognizing the high overlap of psychiatric disorders among both substance abuse and mental health treatment clients. ${ }^{127}$

Pharmacological advances over the past few decades have produced more effective psychiatric medications with fewer side effects that allow individuals with serious and persistent psychopathology to participate in treatment instead of being institutionalized, thus increasing the demand for integrated treatment. However, the development of integrated treatment requires both an understanding of psychopathology and addiction and the means to integrate and modify traditional treatment approaches in both the mental health and addiction treatment fields. ${ }^{128}$ Several strategies found to have promise for dual treatment of substance use and psychiatric disorders include: Motivational Interviewing, Contingency Management, CognitiveBehavioral Therapy, Relapse Prevention, Assertive Community Treatment, and Intensive Case Management. ${ }^{127}$ Randomized control trials are beginning to provide evidence that pharmacologic and psychological interventions are effective. ${ }^{129,130}$ Research is providing information on client factors as well as treatment facility facilitators and barriers to strengthen the integrated dual disorder treatment model. ${ }^{131-134}$ Continuity of care is necessary to guide individuals between service systems and continuing support and aid obtained via self help approaches is needed in the community for long term success.

Understanding the complexity between psychopathology and drug abuse, including the sequencing between both, would help guide us to knowing what to target and when to intervene. ${ }^{135}$ For example, for a young adolescent with CD or ADHD who began using drugs at an early age, an intervention program could have an effect on future drug disorders by reducing current drug use, or by ameliorating current disruptive problem behaviors, or both. A program that targets only the drug use might have little effect on youth at risk for future SUDs because of their history of behavioral problems, while a program targeting only the behavioral problems might have little effect on youth put at risk because of their early drug use. An example of a universal behavioral intervention provided at a very young age, as children enter the educational system, that has been tested in 
community randomized control trials has shown that non-pharmaceutical approaches of prevention may be possible. Teachers use classroom behavior management strategies to socialize children to the student role and reduce aggressive and disruptive behaviors. This strategy, the Good Behavior Game, ${ }^{136}$ has been found to lower the rate of school-based service use (being placed in a special school or special classroom for problems with behavior, feelings, or drug or alcohol; receiving special help in the regular classroom; and receiving other counseling or therapy in school) ${ }^{137}$ and reduce drug and alcohol abuse/dependence disorders, regular smoking, and antisocial personality disorder among males. ${ }^{138}$ Behavior-influence procedures offer a unique opportunity for the prevention of substance use and psychiatric disorders at a public-health level. ${ }^{139}$

Studies pursuing influences and the identification of the mechanisms behind the high co-occurrence of SUDs and psychiatric disorders among youth are needed. We must continue to disentangle the complex temporal relationship. It is important to optimize the research design and methods in order to collect and analyze data that can make further contributions in depicting the interplay and sequencing of symptoms and disorder development.

\section{SUMMARY}

There is strong evidence from clinical and population based studies that SUDs co-occur with externalizing and internalizing disorders, as well as other serious mental health conditions among adolescents. The ramifications and consequences of having comorbid disorders, as opposed to unitary conditions of drug abuse separate from emotional and other behavioral problems, are complex. Traditional treatment and prevention approaches for adolescent well being require modifications to broaden their assessments to detect comorbid conditions. Not only should drug using adolescents be screened for psychopatholgy, but visa versa. In addition the identification and evaluation of comorbid disorders should not be limited to concurrency defined only by one point in time but take into consideration the history of drug involvement and mental health over the entire developmental lifespan. It is imperative that researchers continue to develop a better understanding of the co-occurrence (pre existing or consequential) of substance use and mental illness among youth in hopes of forestalling significant morbidity and mortality, such as disfunctionality or suicide.

Acronyms List:

ADHD = attention-deficit/hyperactivity disorder 
$\mathrm{CD}=$ conduct disorder

DSM = Diagnostic and Statistical Manual of Mental Disorders

ICD = International Classification of Diseases

$\mathrm{MDD}=$ major depressive disorder

NCS-A = The National Comorbidity Survey-Adolescent Supplement

SUD $=$ substance use disorder

About the Authors: Dr. Carla Storr, ScD, MPH, is a professor at the University of Maryland Baltimore School of Nursing. One line of her research is based on the exploration of early childhood markers or signs that might discriminate between differing levels or degrees of involvement with drugs and other psychiatric disorders. Other areas of interest include exploring the influence of environmental factors, such as work demands and neighborhood disadvantage on mental health, and several of her articles explore the emergence of clinical features of drug dependence among recent-onset users.

Lauren R. Pacek is a PhD candidate in the Department of Mental Health at the Johns Hopkins University Bloomberg School of Public Health. She is currently a recipient of a NIDA-funded F31 individual National Research Service Award fellowship, and is a past fellow of the NIDA T32 Drug Dependence Epidemiology Training program. Her research interests include cigarette smoking among HIVpositive populations, substance abuse epidemiology, harm reduction, HIV prevention, and the individual and social environmental factors that contribute to substance use and HIV risk behaviors.

Dr. Silvia Martins, MD, PhD, is a faculty member of the Psych-Neuro cluster of the Department of Epidemiology, Columbia University Mailman School of Public Health. She has been the Principle Investigator and Co-Investigator on several NIH research grants. She is currently the academic coordinator of the NIDA T32 Substance Use Disorders Training Program in the department. Her research focuses on environmental and individual factors associated with substance use and substance use disorders (with a special focus on nonmedical use of prescription drugs), psychiatric disorders and gambling/problem gambling both with US and international data.

Acknowledgements: Portions of this work supported by: DA016323, DA019805, DA023434, HD60072, DA007292 and DA033873.

Conflicts of Interest: None declared.

\section{REFERENCES}

1. Office of National Drug Control Policy. Teens and prescription drugs: An analysis of recent trends on the emerging drug threat. Washington, DC: Office of National Drug Control Policy, Executive Office of the President; 2007.

2. Swendsen J, Burstein M, Case B, Conway KP, Dierker L, et al. Use and abuse of alcohol and illicit drugs in US adolescents: results of the National Comorbidity Survey-Adolescent Supplement. Arch Gen Psychiatry. 2012;69: 390-8. 
3. Dierker L, Swendsen J, Rose J, He J, Merikangas K; Tobacco Etiology Research Network (TERN). Transitions to regular smoking and nicotine dependence in the Adolescent National Comorbidity Survey (NCS-A). Ann Behav Med. 2012;43:394-401.

4. Merikangas KR, He JP, Burstein M, Swanson SA, Avenevoli S, et al. Lifetime prevalence of mental disorders in US adolescents: results from the National Comorbidity Survey Replication-Adolescent Supplement (NCS-A). J Am Acad Child Adolesc Psychiatry. 2010;49:980-9.

5. Armstrong TD, Costello EJ. Community studies on adolescent substance use, abuse, or dependence and psychiatric comorbidity. J Consult Clin Psychol. 2002;70:1224-39.

6. de Graaf R, Bijl RV, Spijker J, Beekman AT, Vollebergh WA. Temporal sequencing of lifetime mood disorders in relation to comorbid anxiety and substance use disorders--findings from the Netherlands Mental Health Survey and Incidence Study. Soc Psychiatry Psychiatr Epidemiol. 2003; 38:1-11.

7. Helzer JE, Pryzbeck TR. The co-occurrence of alcoholism with other psychiatric disorders in the general population and its impact on treatment. J Stud Alcohol. 1988; 49:219-24.

8. Kessler RC, Nelson CB, McGonagle KA, Edlund MJ, Frank RG, Leaf PJ. The epidemiology of co-occurring addictive and mental disorders: implications for prevention and service utilization. Am J Orthopsychiatry. 1996;66:17-31.

9. Krueger RF. The structure of common mental disorders. Arch Gen Psychiatry. 1999;56:921-6.

10. Cosgrove VE, Rhee SH, Gelhorn HL, Boeldt D, Corley RC, et al. Structure and etiology of co-occurring internalizing and externalizing disorders in adolescents. J Abnorm Child Psychol. 2011;39:109-23.

11. Hewitt JK, Silberg JL, Rutter M, Simonoff E, Meyer JM, et al. Genetics and developmental psychopathology: 1. Phenotypic assessment in the Virginia Twin Study of Adolescent Behavioral Development. Child Psychol Psychiatry. 1997;38:943-63.

12. Krueger RF, Caspi A, Moffitt TE, Silva PA. The structure and stability of common mental disorders (DSM-III-R): a longitudinal-epidemiological study. J Abnorm Psychol. 1998;107:216-27.

13. Krueger RF, McGue M, Iacono WG. The higher-order structure of common DSM mental disorders: internalization, externalization, and their connections to personality. Pers Individ Dif. 2001;30:1245-59.

14. Angold A, Costello EJ, Erkanli A. Comorbidity. J Child Psychol Psychiatry. 1999;40:57-87.

15. Wittchen HU, Beesdo-Baum K, Gloster AT, Höfler M, Klotsche J, et al. The structure of mental disorders re-examined: is it developmentally stable and robust against additions? Int J Methods Psychiatr Res. 2009;18:189-203.

16. Olino, TM, Klein, DN, Lewinsohn, PM, Rohde, P, Seeley, JR. Latent trajectory classes of depressive and anxiety disorders from adolescence to adulthood: descriptions of classes and associations with risk factors. Compr Psychiatry. 2010;51:224-35. 
17. Kessler RC, Avenevoli S, McLaughlin KA, Green JG, Lakoma MD, et al. Lifetime co-morbidity of DSM-IV disorders in the US National Comorbidity Survey Replication Adolescent Supplement (NCS-A). Psychol Med. 2012;42: 1997-2010.

18. Moffitt TE, Caspi A, Taylor A, Kokaua J, Milne BJ, et al. How common are common mental disorders? Evidence that lifetime prevalence rates are doubled by prospective versus retrospective ascertainment. Psychol Med. 2010;40:899909.

19. Roberts RE, Roberts CR, Xing Y. Comorbidity of substance use disorders and other psychiatric disorders among adolescents: evidence from an epidemiologic survey. Drug Alcohol Depend. 2007;88:S4-13.

20. Chan YF, Dennis ML, Funk RR. Prevalence and comorbidity of major internalizing and externalizing problems among adolescents and adults presenting to substance abuse treatment. J Subst Abuse Treat. 2008;34:14-24.

21. Bird HR, Gould MS, Staghezza BM. Patterns of diagnostic comorbidity in a community sample of children aged 9 through 16 years. J Am Acad Child Adolesc Psychiatry. 1993;32:361-8.

22. Costello EJ, Erkanli A, Federman E, Angold A. Development of psychiatric comorbidity with substance abuse in adolescents: Effects of timing and sex. J Clin Child Psychol. 1999;28:298-311.

23. KaminerY, Bukstein OG. Adolescent Substance Abuse: Psychiatric Comorbidity and High Risk Behaviors. New York, NY: Haworth Press; 2007.

24. Costello EJ, Mustillo S, Erkanli A, Keeler G, Angold A. Prevalence and development of psychiatric disorders in childhood and adolescence. Arch Gen Psychiatry. 2003;608:837-44.

25. Lewinsohn PM, Rohde P, Seeley JR. Adolescent psychopathology: III. The clinical consequences of comorbidity. J Am Acad Child Adolesc Psychiatry. 1995;34:510-9.

26. Cohen P, Cohen J, Kasen S, Velez CM, Hartmark C, et al. An epidemiological study of disorders in late childhood and adolescence, I. Age- and genderspecific prevalence. J Child Psychol Psychiatry. 1993;34:851-67.

27. Chen KW, Killeya-Jones LA, Vega WA. Prevalence and co-occurrence of psychiatric symptom clusters in the U.S. adolescent population using DISC predictive scales. Clin Pract Epidemiol Ment Health. 2005;1:22.

28. Merikangas KR, He JP, Brody D, Fisher PW, Bourdon K, Koretz DS. Prevalence and treatment of mental disorders among US children in the 2001-2004 NHANES. Pediatrics. 2010;125:75-81.

29. Bourdon KH, Goodman R, Rae DS, Simpson G, Koretz DS. The Strengths and Difficulties Questionnaire: U.S. normative data and psychometric properties. J Am Acad Child Adolesc Psychiatry. 2005;44:557-64.

30. Shaffer D, Fisher P, Dulcan MK, Davies M, Piacentini J, et al. The NIMH Diagnostic Interview Schedule for Children Version 2.3 (DISC-2.3): description, acceptability, prevalence rates, and performance in the MECA Study. Methods for the Epidemiology of Child and Adolescent Mental Disorders Study. J Am Acad Child Adolesc Psychiatry. 1996;35:865-77. 
31. Substance Abuse and Mental Health Services Administration, Office of Applied Studies. The NSDUH Report -Inhalant Use and Major Depressive Episode among Youths Aged 12 to 17: 2004 to 2006. Rockville, MD: SAMHSA; August 21, 2008.

32. Kessler RC, Avenevoli S, Costello EJ, Green JG, Gruber MJ, et al. Design and field procedures in the US National Comorbidity Survey Replication Adolescent Supplement (NCS-A). Int J Methods Psychiatr Res. 2009;18:69-83.

33. Offord DR, Boyle MH, Fleming JE, Blum HM, Grant NI. Ontario Child Health Study. Summary of selected results. Can J Psychiatry. 1989;34:483-91.

34. Fergusson DM, Horwood LJ, Ridder EM. Conduct and attentional problems in childhood and adolescence and later substance use, abuse and dependence: results of a 25-year longitudinal study. Drug Alcohol Depend. 2007;88S:S1426.

35. McGee R, Williams S, Poulton R, Moffitt T. A longitudinal study of cannabis use and mental health from adolescence to early adulthood. Addiction. 2000; 95:491-503.

36. Lieb R, Isensee B, von Sydow K, Wittchen HU. The Early Developmental Stages of Psychopathology Study (EDSP): a methodological update. Eur Addict Res. 2000;6:170-182.

37. Grant BF, Compton WM, Crowley TJ, Hasin DS, Helzer JE, et al. Errors in assessing DSM-IV substance use disorders. Arch Gen Psychiatry. 2007;64: 379-80.

38. Rapee RM, Bögels SM, van der Sluis CM, Craske MG, Ollendick T. Annual research review: conceptualising functional impairment in children and adolescents. J Child Psychol Psychiatry. 2012;53:454-68.

39. Shrier LA, Harris SK, Kurland M, Knight JR. Substance use problems and associated psychiatric symptoms among adolescents in primary care. Pediatrics. 2003;111:e699-705.

40. Costello EJ, Egger H, Angold A. 10-year research update review: the epidemiology of child and adolescent psychiatric disorders: I. Methods and public health burden. J Am Acad Child Adolesc Psychiatry. 2005;44:972-86.

41. Achenbach TM. Integrated guide for the 1991 CBCL/4-18, YSR, and TRF profiles. Burlington, VT: Department of Psychiatry, University of Vermont; 1991.

42. Chen CY, Storr CL, Tang GM, Huang SL, Hsiao CK, Chen WJ. Early alcohol experiences and adolescent mental health: A population-based study in Taiwan. Drug Alcohol Depend. 2008;9:209-18.

43. Substance Abuse and Mental Health Services Administration. The relationship between mental health and substance abuse among adolescents. Rockville, MD: DHHS Publication No. (SMA) 99-3286; 1999.

44. Storr CL, Accornero VH, Crum RM. Profiles of current disruptive behavior: association with recent drug consumption among adolescents. Addict Behav. 2007;32:248-64.

45. Storr CL. Characteristics associated with rapid transition to tobacco dependence in youth. Nicotine Tob Res. 2008;10:1099-104. 
46. Hayatbakhsh MR, Najman J, Jamrozik K, Al Mamun A, Bor W, Alati R. Adolescent problem behaviours predicting DSM-IV diagnoses of multiple substance use disorder. Findings of a prospective birth cohort study. Soc Psychiatry Psychiatr Epidemiol. 2008;43:356-63.

47. McConaughy SH, Achenbach TM. Comorbidity of empirically based syndromes in matched general population and clinical samples. J Child Psychol Psychiatry. 1994;35:1141-57.

48. Kessler RC, Wittchen HU, Abelson JM, McGonagle K, Schwarz N, et al. Methodological studies of the Composite International Diagnostic Interview (CIDI) in the US National Comorbidity Survey. Int J Methods Psychiatr Res. 1998;7:33-55.

49. Wittchen HU, Nelson CB, Lachner G. Prevalence of mental disorders and psychosocial impairments in adolescents and young adults. Psychol Med. 1998;28:109-26.

50. Lewisohn PM, Hops H, Roberts RE, Seeley JR, Andrews JA. Adolescent psychopathology: I. prevalence and incidence of depression and other DSMIII-R disorders in high school students. J Abnorm Psychol. 1993;102:133-44.

51. Kessler RC, Nelson CB, McGonagle KA, Liu J, Swartz M, Blazer DG Comorbidity of DSM-III-R major depressive disorder in the general population: results from the US National Comorbidity Survey. Br J Psychiatry Suppl. 1996;30:17-30.

52. Lewinsohn PM, Shankman SA, Gau JM, Klein DN. The prevalence and co-morbidity of subthreshold psychiatric conditions. Psychol Med. 2004;344: 613-22.

53. Couwenbergh C, van den Brink W, Zwart K, Vreugdenhil C, van WijngaardenCremers P, van der Gaag RJ. Comorbid psychopathology in adolescents and young adults treated for substance use disorders: a review. Eur Child Adolesc Psychiatry. 2006;15:319-28.

54. August GJ, Winters KC, Realmuto GM, Fahnhorst T, Botzet A, Lee, S. Prospective study of adolescent drug use among community samples of ADHD and non-ADHD participants. J Am Acad Child Adolesc Psychiatry. 2006;45:824-32.

55. Kandel DB, Johnson JG, Bird HR, Weissman MM, Goodman SH, et al. Psychiatric comorbidity among adolescents with substance use disorders: Findings from the MECA study. J Am Acad Child Adolesc Psychiatry. 1999; 38:693-9.

56. Randall J, Henggeler SW, Pickrel SG, Brondino MJ. Psychiatric comorbidity and the 16-month trajectory of substance-abusing and substance-dependent juvenile offenders. J Am Acad Child Adolesc Psychiatry.1999;38:1118-24.

57. Rohde P, Lewinsohn PM, Seeley JR. Psychiatric comorbidity with problematic alcohol use in high school students. J Am Acad Child Adolesc Psychiatry. 1996;35:101-9.

58. Wittchen HU, Fröhlich C, Behrendt S, Günther A, Rehm J, et al. Cannabis use and cannabis use disorders and their relationship to mental disorders: a 10-year 
prospective-longitudinal community study in adolescents. Drug Alcohol Depend. 2007;88 Suppl 1:S60-70.

59. Elkins IJ, McGue M, Iacono WG. Prospective effects of attention deficit/ hyperactivity disorder, conduct disorder, and sex on adolescent substance use and abuse. Arch Gen Psychiatry. 2007;64:1145-52.

60. Molina BSG, Pelham WE, Gnagy EM, Thompson AL, Marshal MP. Attention deficit/hyperactivity disorder risk for heavy drinking and alcohol use disorder is age specific. Alcohol Clin Exp Res. 2007;31:643-54.

61. Huizinga D, Elliot DS. A Longitudinal Study of Drug Use and Delinquency in a National Sample of Youth: An Assessment of Causal Order. Project Report No. 16, A National Youth Study. Boulder, CO: Behavioral Research Institute; 1981.

62. Loeber R. Natural histories of conduct problems, delinquency and associated substance use. In: Lahey BB, Kazdin AE, (editors). Advances in Clinical Child Psychology, Volume 11. New York, NY: Plenum; 1988. p.73-124.

63. Hayatbakhsh MR, Najman J, Jamrozik K, Al Mamun A, Bor W, Alati R. Adolescent problem behaviours predicting DSM-IV diagnoses of multiple substance use disorder. Findings of a prospective birth cohort study. Soc Psychiatry Psychiatr Epidemiol. 2008;43:356-63.

64. White HR, Xie M, Thompson W, Loeber R, Stouthamer-Loeber M. Psychopathology as a predictor of adolescent drug use trajectories. Psychol Addict Behav. 2001;15:210-8.

65. Ernst M, Luckenbaugh DA, Moolchan ET, Leff MK, Allen R, et al. Behavioral predictors of substance-use initiation in adolescents with and without attention deficit/hyperactivity disorder. Pediatrics. 2006;117:2030-9.

66. Barkley RA, Fischer M, Smallish L, Fletcher K. Young adult follow-up of hyperactive children: antisocial activities and drug use. J Child Psychol Psychiatry. 2004;45:195-211.

67. O’Neil KA, Conner BT, Kendall PC. Internalizing disorders and substance use disorders in youth: comorbidity, risk, temporal order, and implications for intervention. Clin Psychol Rev. 2011;31:104-12.

68. Wu LT, Gersing K, Burchett B, Woody GE, Blazer DG. Substance use disorders and comorbid Axis I and II psychiatric disorders among young psychiatric patients: findings from a large electronic health records database. J Psychiatr Res. 2011;45:1453-62.

69. Clark DB, Bukstein OG, Smith MG, Kaczynski N, Mezzich AC, Donovan JE. Identifying anxiety disorders in adolescents hospitalized for alcohol abuse or dependence. Psychiatr Serv. 1995;46:618-20.

70. Grella CE, Hser YI, Joshi V, Rounds-Bryant J. Drug treatment outcomes for adolescents with comorbid mental and substance use disorders. J Nerv Ment Dis. 2001;198:384-92.

71. Lubman DI, Allen NB, Rogers N, Cementon E, Bonomo Y. The impact of co-occurring mood and anxiety disorders among substance abusing youth. J Affec Disord. 2007;103:105-12. 
72. Wise BK, Cuffe SP, Fischer T. Dual diagnosis and successful participation of adolescents in substance abuse treatment. J Subst Abuse Treat. 2001;21:161-5.

73. Copeland WE, Angold A, Shanahan L, Dreyfuss J, Dlamini I, Costello EJ. Predicting persistent alcohol problems: a prospective analysis from the Great Smoky Mountain Study. Psychol Med. 2011;13:1-11.

74. Sonntag H, Wittchen, HU, Hofler M, Kessler RC, Stein MB. Are social fears and DSM-IV social anxiety disorder associated with smoking and nicotine dependence in adolescents and young adults? Eur Psychiatry. 2000;15:67-74.

75. Fergusson DM, Horwood LJ, Boden JM. Structural equation modeling of repeated retrospective reports of childhood maltreatment. Int J Methods Psychiatr Res. 2011;20:93-104.

76. Kutcher S, Kachur E, Marton P, Szalai J, Jaunkalns R. Substance abuse among adolescents with chronic mental illnesses: a pilot study of descriptive and differentiating features. Can J Psychiatry. 1992;37:428-31.

77. Gregg L, Barrowclough C, Haddock G. Reasons for increased substance use in psychosis. Clin Psychol Rev. 2007;27:494-510.

78. Kuepper R, van Os J, Lieb R, Wittchen HU, Höfler M, Henquet C. Continued cannabis use and risk of incidence and persistence of psychotic symptoms: 10 year follow-up cohort study. BMJ. 2011;1:342.

79. Larson, M. WebMD. Alcohol-Related Psychosis. 30 March 2006. Medscape Reference. Available from URL: http://emedicine.medscape.com/article/ 289848-overview (Accessed 6 November 2012).

80. Picchioni MM, Murray RM. Schizophrenia. BMJ. 2007;335:91-5.

81. von Ranson KM, Iacono WG, McGue M. Disordered eating and substance use in an epidemiological sample: I. Associations within individuals. Int J Eat Disord. 2002;31:389-403.

82. Root TL, Pisetsky EM, Thornton L, Lichtenstein P, Pedersen NL, Bulik CM. Patterns of co-morbidity of eating disorders and substance use in Swedish females. Psychol Med. 2010;40:105-15.

83. Baker JH, Mitchell KS, Neale MC, Kendler KS. Eating disorder symptomatology and substance use disorders: Prevalence and shared risk in a population based twin sample. Int J Eat Disord. 2010;43:648-58.

84. Gromov I, Gromov D. Sleep and substance use and abuse in adolescents. Child Adolesc Psychiatr Clin N Am. 2009;18:929-46.

85. Shibley HL, Malcolm RJ, Veatch LM. Adolescents with insomnia and substance abuse: consequences and comorbidities. J Psychiatr Pract. 2008;14:146-53.

86. Schilling EA, Aseltine RH Jr, Glanovsky JL, James A, Jacobs D. Adolescent alcohol use, suicidal ideation, and suicide attempts. J Adolesc Health. 2009; 44:335-41.

87. Wilcox HC. Epidemiological evidence on the link between drug use and suicidal behaviors among adolescents. Can Child Adolesc Psychiatr Rev. 2004;13:27-30.

88. Kelly TM, Cornelius JR, Clark DB. Psychiatric disorders and attempted suicide among adolescents with substance use disorders. Drug Alcohol Depend. 2004;73:87-97. 
89. Afifi TO, Cox BJ, Katz LY. The associations between health risk behaviours and suicidal ideation and attempts in a nationally representative sample of young adolescents. Can J Psychiatry. 2007;52:666-74.

90. Wu P, Hoven CW, Liu X, Cohen P, Fuller CJ, Shaffer D. Substance Use, Suicidal Ideation and Attempts in Children and Adolescents. Suicide Life Threat Behav. 2004;34:408-20.

91. Bukstein OG, Brent DA, Perper JA, Moritz G, Baugher M, et al. Risk factors for completed suicide among adolescents with a lifetime history of substance abuse: a case-control study. Acta Psychiatr Scand.1993;88:403-8.

92. O'Connell H, Lawlor BA. Recent alcohol intake and suicidality: a neuropsychological perspective. Ir J Med Sci. 2005;174:51-4.

93. Dierker LC, Aveneovoli S, Merikangas KR, Flaherty BP, Stolar M. Association between psychiatric disorders and the progression of tobacco use behaviors. J Am Acad Child Adolesc Psychiatry. 2001;40:1159-67.

94. Griesler PC, Hu MC, Schaffran C, Kandel DB. Comorbid psychiatric disorders and nicotine dependence in adolescence. Addiction. 2011;106:1010-20.

95. Catalano RF, Hawkins JD. The social development model: a theory of antisocial behavior. In: Hawkins JD, (editor). Delinquency and Crime: Current Theories. New York, NY: Cambridge University Press; 1996. p.149-97.

96. Crowley TJ, Macdonald MJ, Whitmore EA, Mikulich SK. Cannabis dependence, withdrawal, and reinforcing effects among adolescents with conduct symptoms and substance use disorders. Drug Alcohol Depend. 1998;50:2737.

97. Donovan JE, Jessor R, Costa FM. Adolescent problem drinking: stability of psychosocial and behavioral correlates across a generation. J Stud Alcohol. 1999;60:352-61.

98. Jessor R, Jessor SL. Problem Behavior and Psychosocial Development: A Longitudinal Study of Youth. New York, NY: Academic Press; 1977.

99. Kellam SG, Rebok GW. Building developmental and etiological theory through epidemiologically based preventive intervention trials. In: McCord J, Tremblay RE, (editors). Preventing Antisocial Behavior: Interventions from Birth through Adolescence. New York, NY: Guilford Press; 1992. p.162-95.

100. Patterson GR, Reid J, Dishion T. A Social Learning Approach: IV. Antisocial Boys. Eugene, OR: Castalia; 1992.

101. Costello EJ. Psychiatric predictors of adolescent and young adult drug use and abuse: what have we learned? Drug Alcohol Depend. 2007;88:S97-9.

102. Ferdinand RF, Blum M, Verhulst FC. Psychopathology in adolescence predicts substance use in young adulthood. Addiction. 2001;96:861-70.

103. Lee SS, Humphreys KL, Flory K, Liu R, Glass K. Prospective association of childhood attention-deficit/hyperactivity disorder (ADHD) and substance use and abuse/dependence: a meta-analytic review. Clin Psychol Rev. 2011; 31:328-41.

104. van den Bree MB, Pickworth WB. Risk factors predicting changes in marijuana involvement in teenagers. Arch Gen Psychiatry. 2005;62:311-9. 
105. Mackesy-Amiti ME, Fendrich M. Inhalant use and delinquent behavior among adolescents: A comparison of inhalant users and other drug users. Addiction. 1999;94:555-64.

106. King SM, Iacono WG, McGue M. Childhood externalizing and internalizing psychopathology in the prediction of early substance use. Addiction. 2004; 99:1548-59.

107. Brown SA, Gleghorn A, Schuckit MA, Myers MG, Mott MA. Conduct disorder among adolescent alcohol and drug abusers. J Stud Alcohol. 1996;57:314-24.

108. Shrier LA, Harris SK, Kurland M, Knight JR. Substance use problems and associated psychiatric symptoms among adolescents in primary care. Pediatrics. 2003;111:699-705.

109. West R, Gossop M. Overview: a comparison of withdrawal symptoms from different drug classes Addiction. 1994;89:1483-9.

110. Rose RJ, Dick DM, Viken RJ, Pulkkinen L, Kaprio J. Genetic and environmental effects on conduct disorder and alcohol dependence symptoms and their covariation at age 14. Alcohol Clin Exp Res. 2004;28:1541-8.

111. True WR, Heath AC, Scherrer JF, Xian H, Lin N, et al. Interrelationship of genetic and environmental influences on conduct disorder and alcohol and marijuana dependence symptoms. Am J Med Genet. 1999;88:391-7.

112. Kendler KS, Prescott CA, Myers J, Neale MC. The structure of genetic and environmental risk factors for common psychiatric and substance use disorders in men and women. Arch Gen Psychiatry. 2003;60:929-37.

113. Young SE, Smolen A, Corley RP, Krauter KS, DeFries JC, et al. Dopamine transporter polymorphism associated with externalizing behavior problems in children. Am J Med Genet. 2002;114:144-9.

114. Lyons M, Hitsman B, Xian H, Panizzon MS, Jerskey BA, et al. A twin study of smoking, nicotine dependence, and major depression in men. Nicotine Tob Res. 2008;10:97-108.

115. Silberg J, Rutter M, D’Onofrio B, Eaves L. Genetic and environmental risk factors in adolescent substance abuse. J Child Psychol Psychiatry. 2003;44: 664-76.

116. Williamson DE, Ryan ND, Birmaher B, Dahl RE, Kaufman J, et al. A casecontrol family history study of depression in adolescents. J Am Acad Child Adolesc Psychiatry. 1995;34:1596-607.

117. Bruijnzeel AW, Repetto M, Gold MS. Neurobiological mechanisms in addictive and psychiatric disorders. Psychiatr Clin North Am. 2004;27:661-74.

118. Markou A, Kenny PJ. Neuroadaptations to chronic exposure to drugs of abuse: relevance to depressive symptomatology seen across psychiatric diagnostic categories. Neurotox Res. 2002;4:297-313.

119. Rao U. Links between depression and substance abuse in adolescents: neurobiological mechanisms. Am J Prev Med. 2006;31:S161-74.

120. Najt P, Fusar-Poli P, Brambilla P. Co-occurring mental and substance abuse disorders: a review on the potential predictors and clinical outcomes. Psychiatry Res. 2011;186:159-64. 
121. Costello EJ, Copeland W, Cowell A, Keeler G. Service costs of caring for adolescents with mental illness in a rural community, 1993-2000. Am J Psychiatry. 2007;164:36-42.

122. Baker KD, Lubman DI, Cosgrave EM, Killackey EJ, Yuen HP, et al. Impact of co-occurring substance use on 6 month outcomes for young people seeking mental health treatment. Aust N Z J Psychiatry. 2007; 41:896-902.

123. Vida R, Brownlie EB, Beitchman JH, Adlaf EM, Atkinson L, et al. Emerging adult outcomes of adolescent psychiatric and substance use disorders. Addict Behav. 2009;34:800-5.

124. Chander G, Himelhoch S, Fleishman JA, Hellinger J, Gaist P, et al. HAART receipt and viral suppression among HIV-infected patients with co-occurring mental illness and illicit drug use. AIDS Care. 2009;21:655-63.

125. Riggs PD, Whitmore EA. Substance Use Disorders and Disruptive Behavior Disorders. In: Hendren RL (editor). Disruptive Behavior Disorders in Children and Adolescents. Washington, DC: APA Press; 1999. p.133-73.

126. Cornelius JR, Maisto SA, Martin CS, Bukstein OG, Salloum IM, et al. Major depression associated with earlier alcohol relapse in treated teens with AUD. Addict Behav. 2004;29:1035-8.

127. Center for Substance Abuse Treatment. Substance abuse treatment for person with co-occurring disorders Treatment Improvement Protocol (TIP) Series 42. DHHS Publication No. (SMA) 05-3992. Rockville, MD: Substance Abuse and Mental Health Services Administration; 2005.

128. Hawkins EH. A tale of two systems: co-occurring mental health and substance abuse disorders treatment for adolescents. Annu Rev Psychol. 2009;60:197227.

129. Baker AL, Hides L, Lubman DI. Treatment of cannabis use among people with psychotic or depressive disorders: a systematic review. J Clin Psychiatry. 2010;71:247-54.

130. Banham L, Gilbody S. Smoking cessation in severe mental illness: what works? Addiction. 2010;105:1176-89.

131. Thorton LK, Baker AL, Lewin TJ, Kay-Lambkin FJ, Kavanagh D, et al. Reasons for substance use among people with mental disorders. Addict Behav. 2012;37:427-34.

132. Brunette MF, Asher D, Whitley R, Lutz WJ, Wieder BL, et al. Implementation of integrated dual disorders treatment: a qualitative analysis of facilitators and barriers. Psychiatr Serv. 2008;59:989-95.

133. Sterling S, Weisner C, Hinman A, Parthasarathy S. Access to treatment for adolescents with substance use and co-occurring disorders: challenges and opportunities. J Am Acad Child Adolesc Psychiatry. 2010;49:637-66.

134. Brown $\mathrm{CH}$, Bennett ME, Li L, Bellack AS. Predictors of initiation and engagement in substance abuse treatment among individuals with cooccurring serious mental illness and substance use disorders. Addict Behav. 2011;36:439-47. 
135. National Research Council and Institute of Medicine. Preventing mental, emotional, and behavioral disorders among young people: progress and possibilities. In: O’Connell ME, Boat T, Warner KE, (editors). Committee on the Prevention of Mental Disorders and Substance Abuse among Children, Youth, and Young Adults: Research Advances and Promising Interventions. Board on Children, Youth, and Families, Division of Behavioral and Social Sciences and Education. Washington, DC: The National Academies Press; 2009.

136. Barrish HH, Saunders M, Wolf MM. Good behavior game: effects of individual contingencies for group consequences on disruptive behavior in a classroom. J Appl Behav Anal. 1969;2:119-24.

137. Poduska JM, Kellam SG, Wang W, Brown CH, Ialongo NS, Toyinbo P. Impact of the Good Behavior Game, a universal classroom-based behavior intervention, on young adult service use for problems with emotions, behavior, or drugs or alcohol. Drug Alcohol Depend. 2008;95:S29-44.

138. Kellam SG, Brown CH, Poduska JM, Ialongo NS, Wang W, et al. Effects of a universal classroom behavior management program in first and second grades on young adult behavioral, psychiatric, and social outcomes. Drug Alcohol Depend. 2008;95:S5-28.

139. Embry DD. Behavioral vaccines and evidence-based kernels: nonpharmaceutical approaches for the prevention of mental, emotional, and behavioral disorders. Psychiatr Clin North Am. 2011;34:1-34.

140. Chisolm DJ, Mulatu MS, Brown JR. Racial/ethnic disparities in the patterns of co-occurring mental health problems in adolescents in substance abuse treatment. J Subst Abuse Treat. 2009;37:203-10.

141. Clark DB, Pollock N, Bukstein OG, Mezzich AC, Bromberger JT, Donovan JE. Gender and comorbid psychopathology in adolescents with alcohol dependence. J Am Acad Child Adolesc Psychiatry. 1997;36:1195-203.

142. Langenbach T, Sponlein A, Overfeld E, Wiltfang G, Quecke N, et al. Axis I comorbidity in adolescent inpatients referred for treatment of substance use disorders. Child Adolesc Psychiatry Ment Health. 2010;4:25.

143. Molina BSG, Bukstein OG, Lynch KG. Attention-deficit/hyperactivity disorder and conduct disorder symptomatology in adolescents with alcohol use disorder. Psychol Addict Behav. 2002;16:161-4.

144. Tims FM, Dennis ML, Hamilton N, Buchan BJ, Diamond G, et al. Characteristics and problems of 600 adolescent cannabis abusers in outpatient treatment. Addiction. 2002;97:46-57.

145. Whitmore EA, Mikulich SK, Thompson LL, Riggs PD, Aarons, GA, Crowley TJ. Influences on adolescent substance dependence: conduct disorder, depression, attention deficit hyperactivity disorder, and gender. Drug Alcohol Depend. 1997;47:87-97.

146. Chong M, Chan K, Cheng TA. Substance use disorders among adolescents in Taiwan: prevalence, sociodemographic correlates and psychiatric comorbidity. Psychol Med. 1999:29:1387-96. 
147. Disney ER, Elkins IJ, McGue M, Iacono WG. Effects of ADHD, conduct disorder, and gender on substance use and abuse in adolescence. Am J Psychiatry. 1999;156:1515-21.

148. Feehan M, McGee R, Raja SN, Williams SM. DSM-III-R disorders in New Zealand 18-year-olds. Aust N Z J Psychiatry. 1994;28:87-99.

149. Sartor CE, Lynksey MT, Health AC, Jacob T, True W. The role of childhood risk factors in initiation of alcohol use and progression to alcohol dependence. Addiction, 2006;102:216-25.

150. Vreugdenhil C, Van Den Bring W, Wouters L, Doreleijers TAH. Substance use, substance use disorders, and comorbidity patterns in a representative sample of incarcerated male Dutch adolescents. J Nerv Ment Dis. 2003;191: $372-8$.

151. Lambert NM, Hartsough CS. Prospective study of tobacco smoking and substance dependencies among samples of ADHD and non-ADHD participants. J Learn Disabil. 1998;31:533-44.

152. Deykin EY, Levy JC, Wells V. Adolescent depression, alcohol and drug abuse. Am J Public Health. 1987;77:178-81.

153. Hannesdóttir H, Tyrfingsson T, Piha J. Psychosocial functioning and psychiatric comorbidity among substance- abusing Icelandic adolescents. Nord J Psychiatry. 2001;55:43-8.

154. Rowe CL, Liddle HA, Greenbaum PE, Henderson CE. Impact of psychiatric comorbidity on treatment of adolescent drug abusers. J Subst Abuse Treat. 2004;26:129-40.

155. Lansford JE, Erath S, Yu T, Pettit GS, Dodge KA, Bates JE. The developmental course of illicit substance use from age 12 to 22: links with depressive, anxiety, and behavior disorders at age 18. Child Psychol Psychiatry. 2008; 49:877-85.

156. Lewinsohn PM, Zinbarg R, Seeley JR, Lewinsohn M, Sack WH. Lifetime comorbidity among anxiety disorders and between anxiety disorders and other mental disorders in adolescents. J Anxiety Disord. 1997;11:377-94.

157. Rohde P, Lewinsohn PM, Seeley JR. Comorbidity of unipolar depression: II. Comorbidity with other mental disorders in adolescents and adults. J Abnormal Psychology. 1991;100:214-22.

158. Sung M, Erkanli A, Angold A, Costello EJ. Effects of age at first substance use and psychiatric comorbidity on the development of substance use disorders. Drug Alcohol Depend. 2004;75:287-99.

159. Behrendt S, Beesdo-Baum K, Zimmermann P, Höfler M, Perkonigg A, et al. The role of mental disorders in the risk and speed of transition to alcohol use disorders among community youth. Psychol Med. 2011;41:1073-85.

160. Zimmermann P, Wittchen HU, Höfler M, Pfister H, Kessler RC, Lieb R. Primary anxiety disorders and the development of subsequent alcohol use disorders: a 4-year community study of adolescents and young adults. Psychol Med. 2003;33:1211-22. 